\title{
PAR-1 contributes to the innate immune response during viral infection
}

\author{
Silvio Antoniak, ${ }^{1}$ A. Phillip Owens III, ${ }^{1}$ Martin Baunacke, ${ }^{1}$ Julie C. Williams, ${ }^{1}$ Rebecca D. Lee, ${ }^{1}$ \\ Alice Weithäuser, ${ }^{2}$ Patricia A. Sheridan, ${ }^{3}$ Ronny Malz, ${ }^{2}$ James P. Luyendyk, ${ }^{4}$ Denise A. Esserman, ${ }^{5,6}$ \\ JoAnn Trejo, ${ }^{7}$ Daniel Kirchhofer, ${ }^{8}$ Burns C. Blaxall, ${ }^{9}$ Rafal Pawlinski, ${ }^{1}$ Melinda A. Beck, ${ }^{3}$ \\ Ursula Rauch, ${ }^{2}$ and Nigel Mackman ${ }^{1}$
}

\begin{abstract}
1Department of Medicine, Division of Hematology and Oncology, UNC McAllister Heart Institute, University of North Carolina at Chapel Hill, Chapel Hill, North Carolina, USA. ${ }^{2}$ CharitéCentrum 11 - Herz-, Kreislauf- und Gefäßmedizin, Campus Benjamin Franklin, Charité — Universitätsmedizin Berlin, Berlin, Germany. ${ }^{3}$ Department of Nutrition, UNC Gillings School of Global Public Health, University of North Carolina at Chapel Hill, Chapel Hill, North Carolina, USA. 4Department of Pathobiology and Diagnostic Investigation, Michigan State University, East Lansing, Michigan, USA. ${ }^{5}$ Department of Medicine, Division of General Medicine and Clinical Epidemiology, and ${ }^{6}$ Department of Biostatistics, UNC Gillings School of Global Public Health, University of North Carolina at Chapel Hill, Chapel Hill, North Carolina, USA. 7Department of Pharmacology, UCSD, La Jolla, California, USA. ${ }^{8}$ Early Discovery Biochemistry, Genetech Inc.

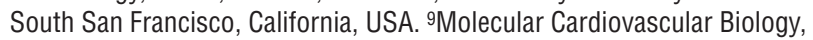
Cincinnati Children's Hospital Medical Center, Cincinnati, Ohio, USA.
\end{abstract}

\begin{abstract}
Coagulation is a host defense system that limits the spread of pathogens. Coagulation proteases, such as thrombin, also activate cells by cleaving PARs. In this study, we analyzed the role of PAR-1 in coxsackievirus B3-induced (CVB3-induced) myocarditis and influenza A infection. CVB3-infected $\mathrm{Par1}^{-/-}$mice expressed reduced levels of IFN- $\beta$ and CXCL10 during the early phase of infection compared with $\mathrm{Par}^{+/+}$mice that resulted in higher viral loads and cardiac injury at day 8 after infection. Inhibition of either tissue factor or thrombin in WT mice also significantly increased CVB3 levels in the heart and cardiac injury compared with controls. BM transplantation experiments demonstrated that PAR-1 in nonhematopoietic cells protected mice from CVB3 infection. Transgenic mice overexpressing PAR-1 in cardiomyocytes had reduced CVB3-induced myocarditis. We found that cooperative signaling between PAR-1 and TLR3 in mouse cardiac fibroblasts enhanced activation of $\mathrm{p} 38$ and induction of IFN- $\beta$ and CXCL10 expression. Par1 ${ }^{-/-}$mice also had decreased CXCL10 expression and increased viral levels in the lung after influenza $\mathrm{A}$ infection compared with $\mathrm{Par} \mathrm{1}^{+/+}$mice. Our results indicate that the tissue factor/thrombin/PAR-1 pathway enhances IFN- $\beta$ expression and contributes to the innate immune response during single-stranded RNA viral infection.
\end{abstract}

\section{Introduction}

Coagulation is an ancient host defense system in invertebrates and vertebrates that limits the spread of pathogens (1-6). In vertebrates, the clotting system is composed of activators, such as the transmembrane protein tissue factor (TF), coagulation proteases, such as thrombin, and the final product, crosslinked fibrin (7). In addition, coagulation proteases can activate cells by cleavage of PARs (8-10). Bacterial and viral infections induce TF expression on various cell types, including monocytes and endothelial cells (11-20). Bacterial LPS induces TF expression in monocytes and endothelial cells via activation of TLR4 (21-23), whereas the TLR3 agonist polyinosinic:polycytidylic acid (poly I:C) induces TF expression in endothelial cells, but not monocytes (17). Uncontrolled TF-dependent activation of coagulation during infection leads to disseminated intravascular coagulation (13, 24-26). Fibrin has been shown to contribute to the innate immune response to bacterial infections by increasing the expression of inflammatory mediators $(5,27)$. In addition, PAR-1 expression is increased in endothelial cells after viral infection $(16,28)$. Interestingly, studies

Conflict of interest: The authors have declared that no conflict of interest exists.

Note regarding evaluation of this manuscript: Manuscripts authored by scientists associated with Duke University, The University of North Carolina at Chapel Hill, Duke-NUS, and the Sanford-Burnham Medical Research Institute are handled not by members of the editorial board but rather by the science editors, who consult with selected external editors and reviewers.

Citation for this article: J Clin Invest. 2013;123(3):1310-1322. doi:10.1172/JCI66125 with cultured endothelial cells found that TF, thrombin, PAR-1, and PAR-2 contribute to the infectivity of the DNA virus herpes simplex virus type $1(29,30)$. Thrombin is the major activator of PAR-1, and this leads to the activation of numerous intracellular signaling pathways, including MAPK pathways $(31,32)$. Interestingly, PAR-1 contributes to the proliferation of cardiac fibroblasts (CFs) and the hypertrophy of cardiomyocytes (33-35). In addition, we and others have shown that PAR-1 plays a role in cardiac injury and remodeling after ischemia-reperfusion injury $(9,36,37)$.

The innate immune response is the first line of defense against pathogens (38). TLRs are a family of receptors that play a central role in host defense by recognizing pathogen-associated molecular patterns (PAMPs) (38). Viral infections are detected by different pattern recognition receptors (PRRs), including TLR3, retinoic acid-inducible gene I (RIG-I) protein, and melanoma differentiation-associated gene-5 (MDA-5) $(39,40)$. These sensors are activated by double-stranded RNA (dsRNA), which is generated as a byproduct of single-stranded RNA (ssRNA) viral replication $(39,41)$. Poly $\mathrm{I}: \mathrm{C}$ is used as a dsRNA mimetic and induces the binding of the adaptor protein Toll/IL-1 receptor/ resistance domain containing adaptor-inducing IFN- $\beta$ (TRIF) to TLR3 homodimers on the cell surface or in endosomes. Subsequently, there is activation of various signaling pathways and transcription factors, including tank binding kinases-1 (TBK-1), IFN regulatory factor-3 (IRF-3), the p38 and JNK MAPKs, and NF-KB (39). TLR3 signaling induces the expression of IFNs, 
A
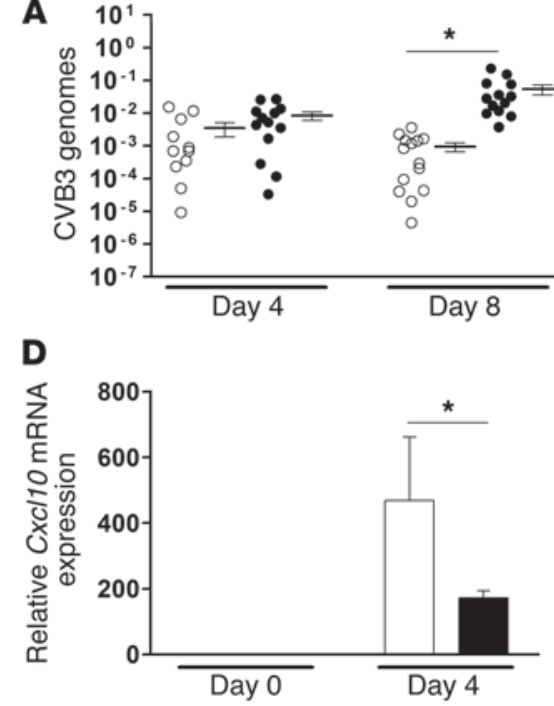

$\mathbf{G}$

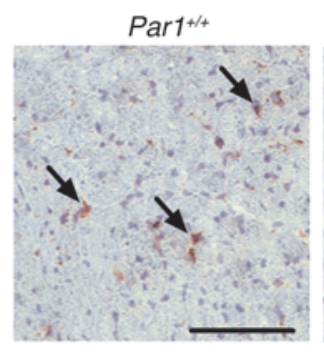

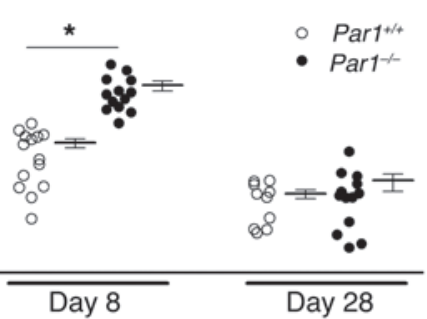

E

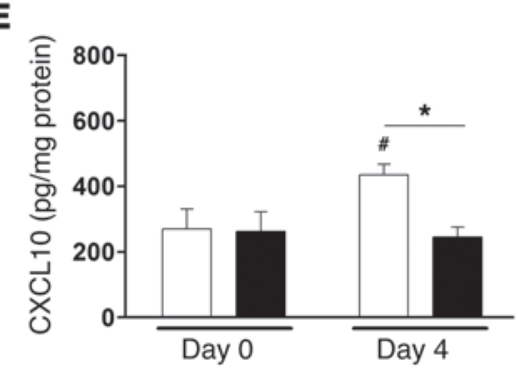

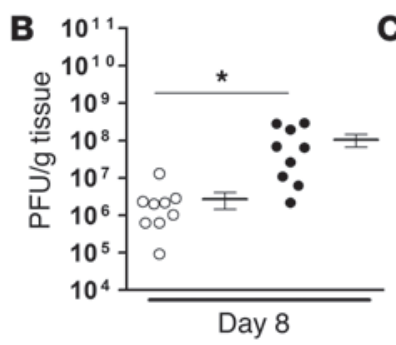

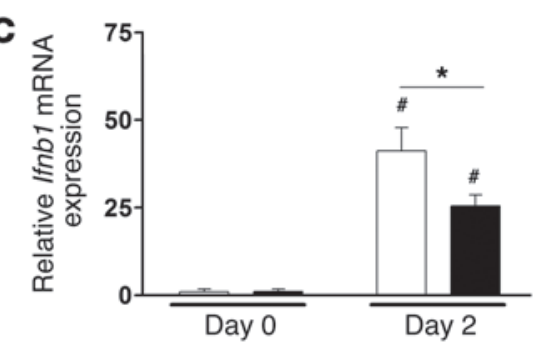

F

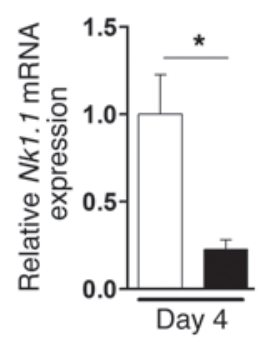

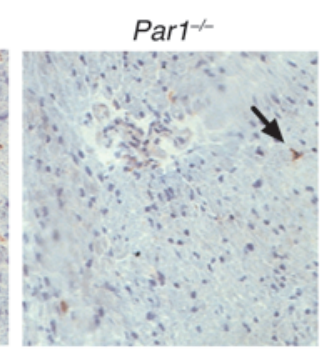

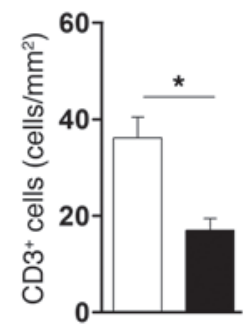

Figure 1

CVB3 levels and the early innate immune response in hearts of Par1 $1^{+/+}$(white symbols and bars) and Par1 $1^{-/-}$(black symbols and bars) mice. (A) Levels of CVB3 genomes at different times after CVB3 infection. (B) CVB3 virus titers at 8 dpi. (C-E) Levels of Ifnb1 mRNA (C), Cxcl10 mRNA (D), and CXCL10 protein (E) expression before infection and at 2 or 4 dpi. (F and G) Levels of the NK cell-specific mRNA Nk1.1 (F) and number of $\mathrm{CD}^{+}$cells $(\mathbf{G})$ at 4 dpi. Nk1.1 mRNA expression is shown relative to the level in infected Par1 ${ }^{+/+}$hearts. Representative images are shown. Arrows indicate staining of CD3 ${ }^{+}$cells. Scale bar: $100 \mu \mathrm{m}$. Data (mean $\pm \mathrm{SEM} ; n=4-10$ per group) were analyzed by 2 -way ANOVA (A-E) or 2-tailed Student's $t$ test $(\mathbf{F}$ and $\mathbf{G}) .{ }^{*} P<0.05 ;{ }^{\#} P<0.05$ vs. respective genotype at day 0 .

which initiate early innate immune responses to viruses $(42,43)$. IFNs are divided into type I (IFN- $\alpha$ and IFN- $\beta$ ), type II (IFN- $\gamma$ ), and type III (IFN- $\lambda$ ). Ifnb1 gene expression requires the activation of various intracellular signaling pathways, including the JNK and p38 MAPKs and the transcription factors AP-1, NF- $\mathrm{KB}$, and IRF-3 $(42,44)$. Furthermore, TLR3-mediated p38 MAPK activation stabilizes Ifnb1 mRNA (45).

Infections with cardiotropic viruses, such as the ssRNA virus coxsackievirus B3 (CVB3), can result in myocarditis, dilated cardiomyopathy, and heart failure (46). Although the virus is directly responsible for some organ injury, the majority of the injury is caused by the host inflammatory response to the virus (46). TLR3 or TRIF deficiency is associated with increased viral titers and a higher mortality after infection with CVB3 or CVB4 (47-49). Type I IFN signaling, but not type II IFN signaling, is required for an innate immune response to CVB3 infection (50). Indeed, IFN- $\beta$ deficient mice are more susceptible than WT mice to infection with CVB3 (51). Importantly, administration of IFN- $\alpha$ or IFN- $\beta$ reduces CVB3-induced myocarditis in mice and humans (48, 52, 53). Similarly, the ssRNA virus influenza A activates both TLR3 and RIG-I in lung epithelial cells (54). IFN- $\alpha$ and $-\beta$ are expressed at low levels by numerous cell types, such as CFs, cardiomyo- cytes, and epithelial cells, and are induced in virus-infected cells to reduce viral replication $(43,55)$. IFNs induce the expression of various chemokines, such as CXCL10 (also called IP-10), and mice lacking CXCL10 have increased cardiac injury after CVB3 infection $(56,57)$. One role of CXCL10 is to recruit NK cells and CD3 ${ }^{+}$ leukocytes to the site of infection to prevent the spread of infection by removing virally infected cells $(56,57)$.

TLRs and PARs have been proposed to act as a dual-sensor system to detect infection: TLRs are activated by PAMPs, and PARs are activated by proteases, including coagulation proteases (58). Others have proposed that PARs play roles in both innate and adaptive immunity $(59,60)$. The majority of studies have focused on PAR2 . An early study reported that PAR-2 enhanced TLR4 signaling in macrophages and epithelial cells (61), whereas a more recent study found that activation of PAR-2 in primary mouse macrophages reduced LPS induction of proinflammatory cytokines and increased the expression of the antiinflammatory cytokine IL-10 (62). In addition, PAR-2 was shown to suppress TLR3 signaling in lung epithelial cells, and PAR-2-deficient mice were protected against influenza A infection (63). However, a second study found that PAR-2-dependent expression of IFN- $\gamma$ protected mice against influenza A infection (64). To date, the role of PAR-1 in the innate 
A
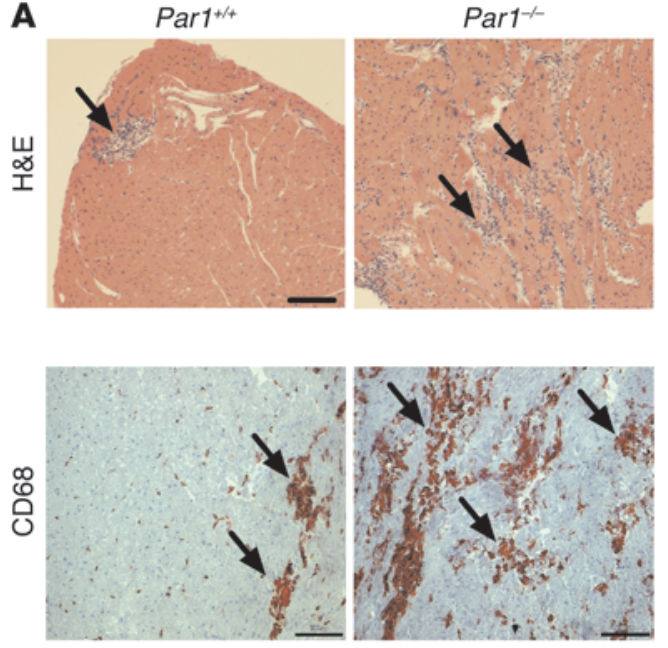

B

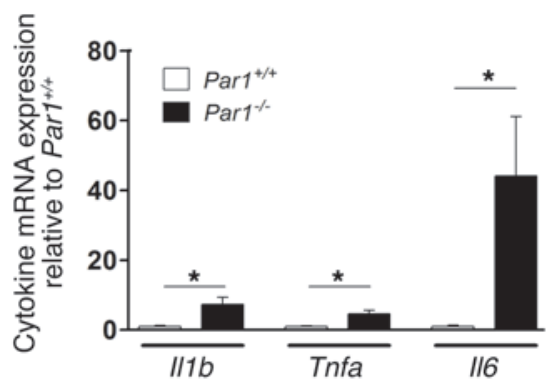

immune response to ssRNA viral infection has not been studied in mice. Here, we investigated the role of PAR-1 in CVB3-induced myocarditis and influenza A infection.

\section{Results}

Par1 $1^{-1-}$ mice have increased levels of CVB3 in the liver and heart. CVB3 infection of $\mathrm{C} 57 \mathrm{BL} / 6$ mice leads to viral infection and replication in primary sites, such as the liver, at 2-4 days post infection (dpi), followed by secondary infection of the heart, with maximal levels of viral genomes observed at $8 \mathrm{dpi}(65)$. Therefore, we measured levels of CVB3 in livers and hearts of $\mathrm{Parl}^{+/+}$and $\mathrm{Par}^{1^{-/}}$mice at various times after infection. Mice were infected at 6-8 weeks of age via i.p. injection of $1 \times 10^{5} \mathrm{PFU}$ purified CVB3 and analyzed at $2,4,8$, and $28 \mathrm{dpi}$. These time points were chosen to investigate the 3 phases of myocarditis: early (2-4 dpi; early viral replication), acute ( $8 \mathrm{dpi}$; maximal viral infection and cellular infiltration into the heart), and chronic (28 dpi; viral clearance and heart dysfunction) (65). Par1 $1^{-/-}$mice had significantly higher levels of virus in the liver than did $\mathrm{Parl}^{+/+}$mice at $8 \mathrm{dpi}$ (Supplemental Figure 1A; supplemental material available online with this article; doi:10.1172/JCI66125DS1). In the heart, we observed significantly

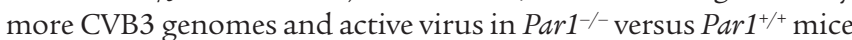
at $8 \mathrm{dpi}$ (Figure 1, A and B). No difference between genotypes was observed in the heart at 4 or $28 \mathrm{dpi}$ (Figure 1A).

Par1 $1^{-/}$mice have reduced Ifnb1 and CXCL10 expression at 2 and 4 $d p i$. We speculated that the increased levels of CVB3 genomes in $\mathrm{Par}^{-/-}$mice may be due to reduced virus killing caused by reduced expression of the IFN- $\beta$ /CXCL10 antiviral pathway. This pathway has been shown to play a central role in protecting mice against CVB3 infection $(50,51,56,57)$. Therefore, we

\section{Figure 2}

Inflammation in the hearts of CVB3-infected Par1 $1^{+/+}$and Par1 $1^{-1}$ mice. (A) Levels of cellular infiltrates and CD68 ${ }^{+}$ cells in Par1 ${ }^{+/+}$(white bars) and Par1-/- (black bars) hearts at 8 dpi. Representative images are shown. Arrows indicate areas of inflammatory cells (top) and $\mathrm{CD}^{2} 8^{+}$cells (bottom). Scale bars: $100 \mu \mathrm{m}$. (B) Inflammatory mediators in Par1/++ and $\mathrm{Par1}^{-1-}$ hearts at $8 \mathrm{dpi}$. Results are shown relative to mRNA expression level in infected $\mathrm{Par}^{+/++}$hearts. Data (mean \pm SEM; $n=4-10$ per group) were analyzed by 2 -tailed Student's $t$ test. ${ }^{*} P<0.05$.

measured the levels of Ifnb1 mRNA expression and the IFN response gene CXCL10 in the heart before and after CVB3 infection. We observed lower levels of Ifnb1 mRNA expression in the hearts of $\mathrm{Par1}^{-/-}$compared with $\mathrm{Parl}^{+/+}$mice at $2 \mathrm{dpi}$ (Figure 1C). Similarly, Par1 $1^{-/-}$hearts had lower levels of Cxcl10 mRNA and CXCL10 protein expression at 4 dpi compared with $\mathrm{Parl}^{+/+}$hearts (Figure 1, D and E). Levels of CXCL10 expression were also significantly reduced in the livers of $\mathrm{Par1}^{-/-}$compared with $\mathrm{Parl}^{+/+}$mice (Supplemental Figure 1B). Since CXCL10 recruits NK cells and $\mathrm{CD}^{+}$leukocytes into infected organs $(56,66)$, we analyzed early infiltration of these cells into the hearts of infected $\mathrm{Parl}^{+/+}$and $\mathrm{Parl}^{-/-}$mice. At $4 \mathrm{dpi}$, hearts of $\mathrm{Parl}^{-/-}$mice had significantly lower levels of Nk1.1 mRNA, which is expressed by NK cells, and lower numbers of $\mathrm{CD}^{+}$cells compared with $\mathrm{Parl}^{+/+}$ mice (Figure 1, F and G).

Par1 ${ }^{-1-}$ mice have increased inflammation in the heart at 8 dpi. CVB3 infection leads to inflammation and infiltration of immune cells into the heart (14). We hypothesized that the higher level of CVB3 at $8 \mathrm{dpi}$ observed in $\mathrm{Par1}^{-/-}$mice will evoke a higher level of inflammation and infiltration of immune cells. We analyzed infiltration of immune cells into the hearts of CVB3infected $\mathrm{Parl}^{+/+}$and $\mathrm{Parl}^{-/-}$mice by H\&E and staining for CD68, and inflammation was assessed by measuring levels of various cytokine mRNAs. As expected, Par1 $1^{-/-}$hearts had higher levels of inflammatory cell infiltrates and $\mathrm{CD} 68^{+}$cells than $\operatorname{did} \mathrm{Parl}^{+/+}$ hearts at $8 \mathrm{dpi}$ (Figure 2A). In addition, levels of Il1b, Il6, and Tnfa mRNA expression were significantly higher in $\mathrm{Parl}^{-/-}$versus $\mathrm{Parl}^{+/+}$hearts at $8 \mathrm{dpi}$ (Figure 2B).

Par1 $1^{-1-}$ mice have increased cardiac injury and dysfunction at $8 \mathrm{dpi}$. CVB3-induced myocarditis leads to cardiac injury and heart failure (14). We used plasma cardiac troponin I as a measure of cardiac injury. Levels of plasma cardiac troponin I increased at $4 \mathrm{dpi}$ and peaked at $8 \mathrm{dpi}$ in both $\mathrm{Parl}^{1^{++}}$and $\mathrm{Parl}^{-/-}$mice (Figure 3A). However, Par1 $1^{-/}$mice had significantly higher levels of cardiac troponin I than did Parl $^{+/+}$mice at $8 \mathrm{dpi}$ (Figure $3 \mathrm{~A})$. Next, we measured cardiac hypertrophy by assessing heart weight/BW (HW/BW) ratios and dilation of the LV by echocardiography before CVB3 infection and at $28 \mathrm{dpi}$. Heart function was measured by examining the change in percent fractional shortening (FS) of the hearts, which was calculated from ventricle dimensions assessed by echocardiography (Table 1$)$. We observed a significant increase in $\mathrm{HW} / \mathrm{BW}$ ratio in $\mathrm{Par1}^{-/-}$, but not $\mathrm{Parl}^{+/+}$, mice (Figure 3B). CVB3 infection also significantly increased cardiac hypertrophy and significantly decreased heart function in both $\mathrm{Parl}^{+/+}$and $\mathrm{Parl}^{-/-}$mice (Figure 3, C and D). 
A

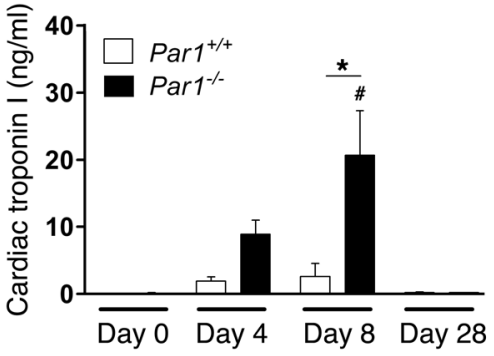

C

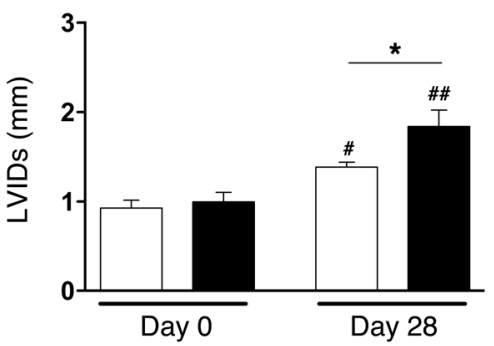

B

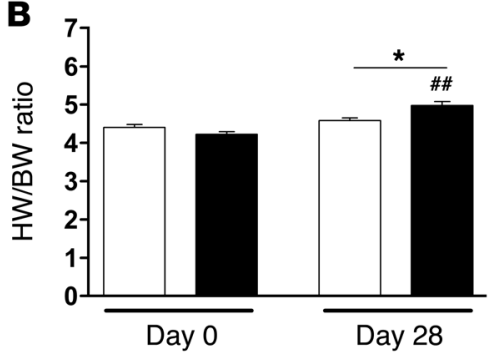

\section{Figure 3}

Cardiac injury and function in $\mathrm{Par} \mathrm{1}^{+/+}$and $\mathrm{Par1} 1^{-/-}$mice after CVB3 infection. (A) Cardiac troponin I levels in plasma of Par1+/+ (white bars) and Par1-/- (black bars) mice before and at different time points after CVB3 infection. (B) HW/BW ratios before infection and at 28 dpi. (C) Echocardiographic analysis of systolic LV internal diameter (LVID-s) and (D) FS before infection and at $28 \mathrm{dpi}$. Data (mean \pm SEM; $n=5-9$ per group) were analyzed by 2 -way ANOVA. ${ }^{*} P<0.05$; ${ }^{\#} P<0.05$, $\# P<0.01$ vs. respective genotype at day 0 .

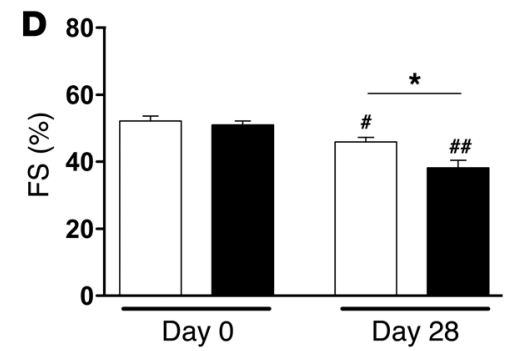

However, there was a significantly larger dilation of the LV and a significantly greater decrease in heart function in infected Par1 ${ }^{-/-}$versus Par $^{+/+}$mice (Figure 3, C and D).

Role of PAR-1 expression by hematopoietic and nonbematopoietic cells in CVB3-induced myocarditis. To analyze the role of PAR-1 on either hematopoietic or nonhematopoietic cells in CVB3 infection, we

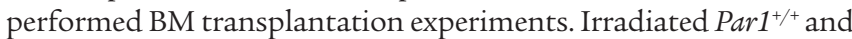
$\mathrm{Parl}^{-/-}$mice were transplanted with either $\mathrm{Parl}^{+/+}$or $\mathrm{Parl}^{-/-} \mathrm{BM}$ to create 4 chimeric groups of mice. As expected, there were significantly higher levels of CVB3 genomes and plasma cardiac troponin $\mathrm{I}$ in the $\mathrm{Par1}^{-/-} \mathrm{BM} \rightarrow \mathrm{Parl}^{-/-}$transplant group than in the $\mathrm{Parl}^{+/+}$ $\mathrm{BM} \rightarrow \mathrm{Parl}^{+/+}$group at $8 \mathrm{dpi}$ (Figure $4, \mathrm{~A}$ and B). Par1 $1^{-/-} \mathrm{BM} \rightarrow \mathrm{Parl}^{+/+}$ mice (with PAR-1 deficiency in hematopoietic cells) had a slightly higher level of CVB3 genomes than did $\mathrm{Parl}^{+/+} \mathrm{BM} \rightarrow \mathrm{Parl}^{+/+}$mice, whereas $\mathrm{Parl}^{+/+} \mathrm{BM} \rightarrow \mathrm{Par1}^{-/-}$mice (with PAR-1 deficiency in nonhematopoietic cells) had slightly higher levels of CVB3 genomes than did $\mathrm{Parl}^{-/-} \mathrm{BM} \rightarrow \mathrm{Parl}^{-/}$mice (Figure 4A). We next assessed cardiac injury and found slightly higher cardiac troponin I levels in $\mathrm{Parl}^{-/-} \mathrm{BM} \rightarrow \mathrm{Parl}^{+/+}$than in $\mathrm{Parl}^{+/+}$ $\mathrm{BM} \rightarrow \mathrm{Par}^{+/+}$mice, whereas cardiac troponin I levels of $\mathrm{Parl}^{+/+} \mathrm{BM} \rightarrow \mathrm{Par1}^{-/}$mice were intermediate between the $\mathrm{Par1}^{-/-} \mathrm{BM} \rightarrow \mathrm{Parl}^{-/-}$and $\mathrm{Parl}^{+/+}$ $\mathrm{BM} \rightarrow \mathrm{Parl}^{+/+}$control groups (Figure 4B). These results suggest that PAR-1 on nonhematopoietic cells plays a more important role in CVB3 infection than PAR-1 on hematopoietic cells. The differences between CVB3 genomes and cardiac troponin I levels may indicate different roles for PAR-1 in viral infection versus cardiac injury.

Mice overexpressing PAR-1 on cardiomyocytes are protected from CVB3-induced myocarditis. Previously, we generated $\alpha$ MHCPAR-1 mice, which overexpress PAR- 1 on cardiomyocytes using the $\alpha$-myosin heavy chain ( $\alpha \mathrm{MHC}$ ) promoter (36). We hypothesized that these mice may be protected from CVB3-induced myocarditis. $\alpha$ MHCPAR-1 mice and littermate WT controls were infected with CVB3, and CXCL10 expression as well as levels of viral

\section{Table 1}

genomes and inflammation were measured at 4 and $8 \mathrm{dpi}$. We found that $\alpha$ MHCPAR- 1 mice had significantly increased CXCL10 expression in the heart at $4 \mathrm{dpi}$ compared with littermate controls (Figure 5A). Furthermore, $\alpha$ MHCPAR-1 mice had decreased levels of virus in the heart, but not in the liver, at $8 \mathrm{dpi}$ compared with WT mice (Figure 5, B and C). The decrease in virus in the hearts of $\alpha$ MHCPAR-1 mice was associated with a significant reduction in inflammatory cell infiltrates in the heart, Tnfa mRNA expression, and cardiac injury compared with WT littermates at $8 \mathrm{dpi}$ (Figure 5, D-F). Levels of Illb and Il6 mRNA were also reduced in the hearts of $\alpha$ MHCPAR-1 mice compared with littermates (Figure $5 \mathrm{E}$ ). These results indicate that overexpression of PAR-1 on cardiomyocytes protects mice against CVB3-induced myocarditis.

Role of TF and thrombin in CVB3-induced myocarditis. Virus infection is associated with TF-dependent activation of coagulation and the generation of thrombin, the major activator of PAR-1 in vivo (12-17). Previously, we found that TF protein expression was increased in

Heart function analysis by echocardiography before CVB3 infection and at $28 \mathrm{dpi}$

\begin{tabular}{|c|c|c|c|c|}
\hline & \multicolumn{2}{|c|}{ Before infection } & \multicolumn{2}{|c|}{$28 \mathrm{dpi}$} \\
\hline & Par1+/+ & Par1-/ & Par1+/+ & Par1-/- \\
\hline $\begin{array}{l}\text { LVID-d (mm) } \\
\text { LVID-s (mm) }\end{array}$ & $\begin{array}{l}2.68 \pm 0.11 \\
0.92 \pm 0.09\end{array}$ & $\begin{array}{l}2.52 \pm 0.07 \\
1.00 \pm 0.11\end{array}$ & $\begin{array}{l}2.50 \pm 0.07 \\
1.39 \pm 0.05^{\mathrm{A}}\end{array}$ & $\begin{array}{l}2.74 \pm 0.18 \\
1.84 \pm 0.19 \mathrm{~B}, \mathrm{C}\end{array}$ \\
\hline $\begin{array}{l}\text { LVPW-d (mm) } \\
\text { LVPW-s (mm) }\end{array}$ & $\begin{array}{l}1.29 \pm 0.05 \\
1.74 \pm 0.04\end{array}$ & $\begin{array}{l}1.29 \pm 0.07 \\
1.64 \pm 0.08\end{array}$ & $\begin{array}{l}0.91 \pm 0.05^{\mathrm{B}} \\
1.26 \pm 0.07^{\mathrm{B}}\end{array}$ & $\begin{array}{l}0.90 \pm 0.06^{B} \\
1.21 \pm 0.05^{B}\end{array}$ \\
\hline $\begin{array}{l}\text { LVAW-d (mm) } \\
\text { LVAW-s (mm) }\end{array}$ & $\begin{array}{l}1.26 \pm 0.05 \\
1.69 \pm 0.05\end{array}$ & $\begin{array}{l}1.25 \pm 0.03 \\
1.68 \pm 0.05\end{array}$ & $\begin{array}{l}0.99 \pm 0.05^{\mathrm{B}} \\
1.39 \pm 0.06^{\mathrm{B}}\end{array}$ & $\begin{array}{l}1.04 \pm 0.06^{\mathrm{A}} \\
1.40 \pm 0.05^{\mathrm{A}}\end{array}$ \\
\hline $\begin{array}{l}\text { LV vol-d }(\mu \mathrm{l}) \\
\text { LV vol-s }(\mu \mathrm{l})\end{array}$ & $\begin{array}{r}27.19 \pm 2.75 \\
4.18 \pm 0.45\end{array}$ & $\begin{array}{r}23.11 \pm 1.75 \\
3.77 \pm 0.46\end{array}$ & $\begin{array}{r}21.92 \pm 1.62 \\
5.31 \pm 0.50\end{array}$ & $\begin{array}{l}30.35 \pm 5.52 \\
11.28 \pm 3.24 \mathrm{~A}, \mathrm{C}\end{array}$ \\
\hline $\begin{array}{l}\text { EF (\%) } \\
\text { FS (\%) }\end{array}$ & $\begin{array}{l}84.71 \pm 1.30 \\
52.27 \pm 1.47\end{array}$ & $\begin{array}{l}83.97 \pm 1.01 \\
51.04 \pm 1.10\end{array}$ & $\begin{array}{l}79.12 \pm 1.31 \\
45.97 \pm 1.33^{\mathrm{A}}\end{array}$ & $\begin{array}{l}69.61 \pm 3.24 \mathrm{~A}, \mathrm{C} \\
38.24 \pm 2.27^{\mathrm{B}, \mathrm{C}}\end{array}$ \\
\hline
\end{tabular}

-d, diastolic; -s systolic; LVID, LV internal diameter; LVPW, LV posterior wall thickness; LVAW, LV anterior wall thickness; LV vol, LV volume; EF, ejection fraction. Data (mean \pm SEM; $n=5-9$ per group) were analyzed by 2 -way ANOVA. ${ }^{A} P<0.05,{ }^{B} P<0.01$ vs. respective genotype before infection; ${ }^{C} P<0.05$ versus $28 \mathrm{dpi} P a r 1^{+/+}$. 

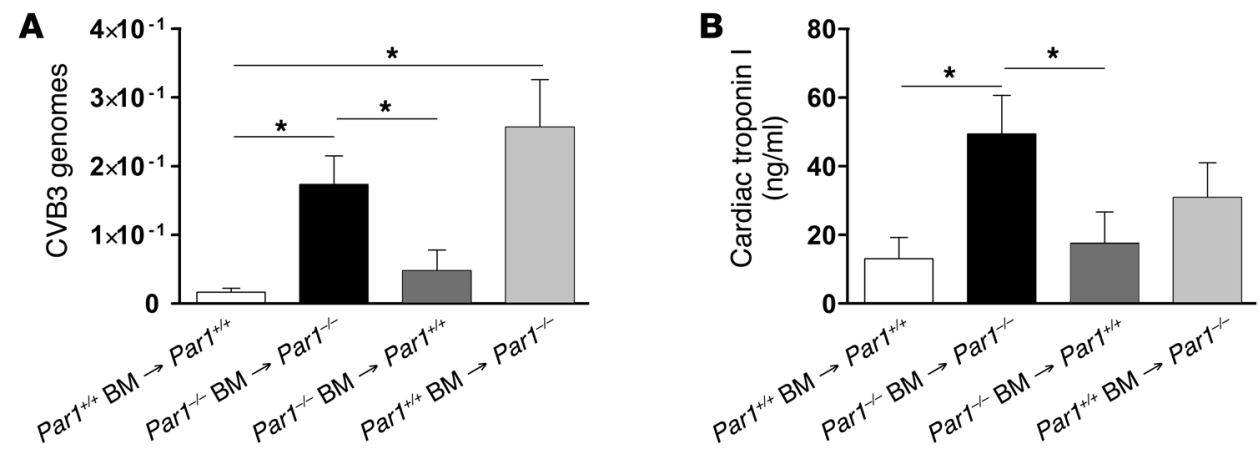

Figure 4

Cellular sources of PAR-1 that contribute to protection from CVB3-induced myocarditis. CVB3 genomes in the heart (A) and cardiac injury (B) in CVB3-infected control Par1+/+ BM $\rightarrow$ Par1 ${ }^{+/+}$and Par1 ${ }^{-/-} \mathrm{BM} \rightarrow P$ Par1 $1^{-/-}$chimeric mice, Par1 ${ }^{-/-} \mathrm{BM} \rightarrow P$ Par1 ${ }^{+/+}$mice (PAR-1 deficiency in hematopoietic cells), and Par1+/+ BM $\rightarrow$ Par1-/- mice (PAR-1 deficiency in nonhematopoietic cells) at 8 dpi. Data (mean \pm SEM; $n=4-10$ per group) were analyzed by 2 -way ANOVA. ${ }^{*} P<0.05$.

the hearts of CVB3-infected WT mice at $8 \mathrm{dpi}$, and this was associated with increased fibrin deposition (14). In this study, we analyzed levels of $T f$ mRNA expression in the heart and the activation of coagulation in the circulation of WT mice at different times after CVB3 infection. We used levels of plasma thrombin-antithrombin (TAT) complexes as a marker of activation of coagulation. We found that $T f$ mRNA expression was transiently induced in the heart, with maximal levels at $4 \mathrm{dpi}$ (Figure 6A). Tf mRNA expression was also increased in the liver of CVB3-infected mice at $4 \mathrm{dpi}$ (Supplemental Figure 1C). We observed a significant increase in plasma TAT levels at 4 and 8 dpi (Figure 6B). Next, we analyzed fibrin deposition in the hearts of CVB3-infected mice. Fibrin was observed in the myocardium adjacent to areas of infiltrating immune cells (Figure 6C).

To investigate the role of TF in CVB3-induced myocarditis, WT mice were given either a rat anti-mouse TF-inhibitory monoclonal antibody $(1 \mathrm{H} 1 ; 20 \mathrm{mg} / \mathrm{kg})$ or a rat IgG2a $(20 \mathrm{mg} / \mathrm{kg})$ via i.p. injection 1 day before CVB3 infection and at 2 and 5 dpi (67), then euthanized at $8 \mathrm{dpi}$. We found that inhibition of TF significantly increased levels of CVB3 genomes and cardiac injury compared with uninhibited controls (Figure 7, A and
B). Next, we determined the effect of inhibiting thrombin on CVB3-induced myocarditis by feeding WT mice an AIN-93M chow diet containing peanut flavoring with or without dabigatran etexilate ( $10 \mathrm{~g} / \mathrm{kg}$ chow) for 7 days prior to CVB3 infection and at $8 \mathrm{dpi}$. The level of anticoagulation was assessed by measuring the activated partial thromboplastin time (aPTT) in both groups. Mice fed the dabigatran etexilate diet had significant aPTT prolongation compared with mice fed a placebo diet $(25.00 \pm 0.97$ vs. $68.15 \pm 7.11$ seconds; $P<0.001)$. We found that inhibition of thrombin significantly increased viral genomes in the hearts and cardiac injury at $8 \mathrm{dpi}$ compared with WT mice that received normal chow (Figure 7, C and D). These results indicate that both $\mathrm{TF}$ and thrombin play a role in CVB3induced myocarditis.

Thrombin not only activates PAR-1, but also activates PAR-4 and cleaves fibrinogen. To determine whether thrombin has effects beyond simply activating PAR-1, we compared the effect of inhibiting thrombin in $\mathrm{Parl}^{-/-}$and $\mathrm{Parl}^{+/+}$mice. We found that $\mathrm{Parl}^{-/-}$ mice had significantly higher levels of CVB3 genomes and cardiac injury than did thrombin-inhibited $\mathrm{Parl}^{+/+}$mice (Figure 7, E and
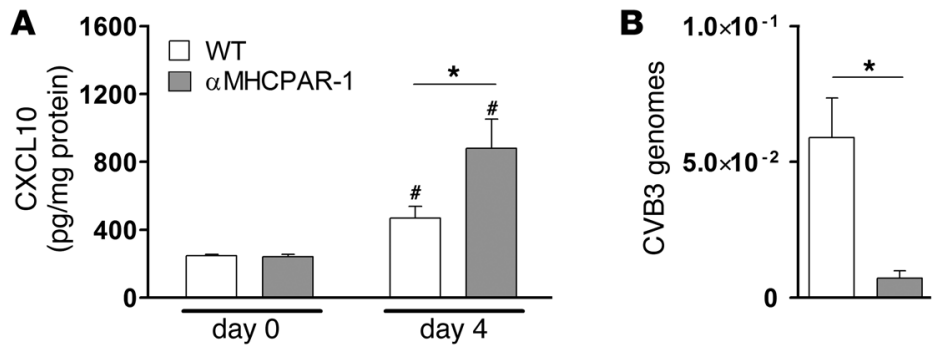

D
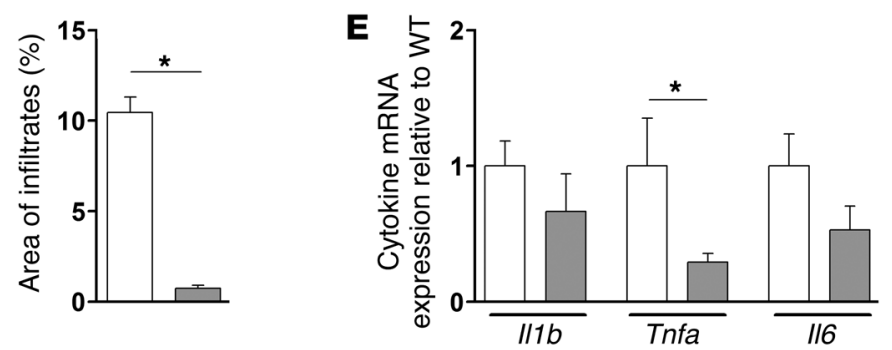

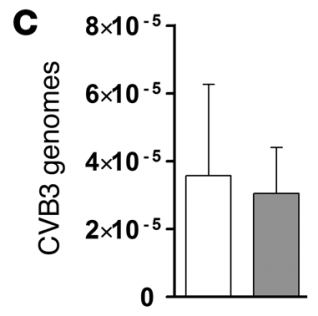

$\mathbf{F}$

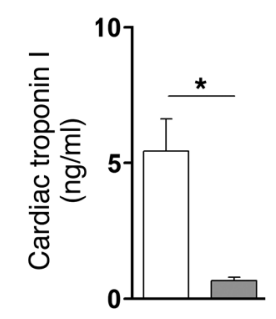

Figure 5

Overexpression of PAR-1 reduces CVB3-induced myocarditis. WT (white) and $\alpha$ MHCPAR-1 (gray) animals were infected with CVB3. (A) CXCL10 protein levels in heart at 4 dpi. (B and C) Number of CVB3 genomes in heart (B) and liver (C) at $8 \mathrm{dpi}$. (D) Levels of inflammatory cell infiltrates in heart at 8 dpi. (E) //1b, Tnfa, and II6 mRNA expression in heart at 8 dpi. mRNA expression for each gene is shown relative to WT. (F) Circulating cardiac troponin I at 8 dpi. Data (mean \pm SEM; $n=4-9$ per group) were analyzed by 2-way ANOVA (A) or 2-tailed Student's $t$ test $(\mathbf{B}-\mathbf{F}) .{ }^{*} P<0.05 ;{ }^{*} P<0.05$ vs. respective genotype at day 0 . 

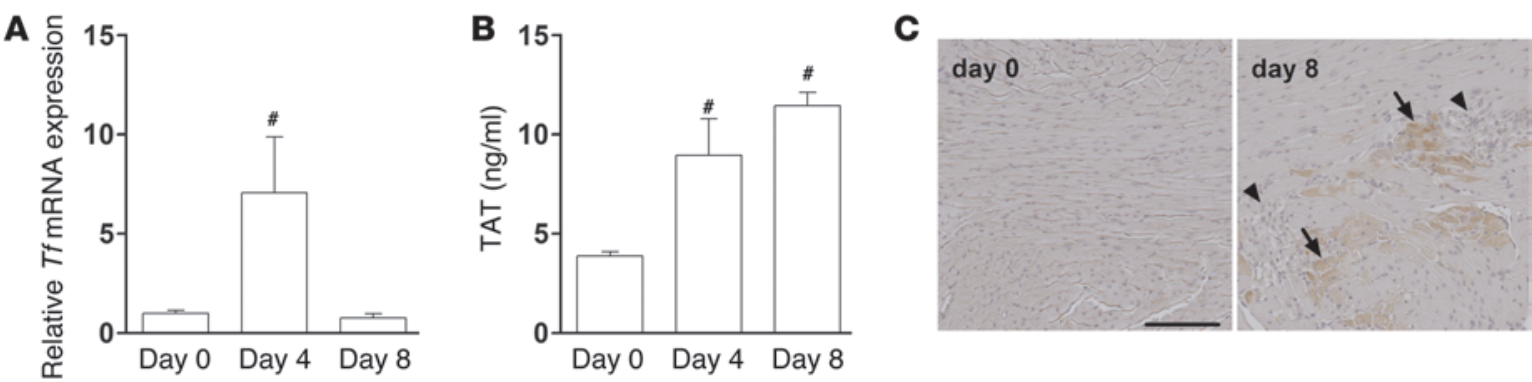

\section{Figure 6}

TF expression, TAT levels, and fibrin deposition in the hearts of infected WT mice. Tf mRNA expression (A), plasma TAT levels (B), and fibrin(ogen) staining (C) in control and CVB3-infected WT hearts. Arrows indicate fibrin staining (brown); arrowheads indicate inflammatory cell infiltrates. Scale bar: $100 \mu \mathrm{m}$. Data (mean $\pm \mathrm{SEM} ; n=4-14$ per group) were analyzed by 1-way ANOVA. ${ }^{\prime} P<0.05$ vs. day 0 .

F). Surprisingly, inhibition of thrombin in $\mathrm{Parl}^{-1-}$ mice reduced levels of CVB3 genomes and cardiac troponin I compared with Par1 $1^{-1}$ mice fed normal chow (Figure 7, E and F).

Stimulation of PAR-1 on cardiac fibroblasts enhances TLR 3 activation of p38 and induction of IFN- $\beta$ and CXLC10 expression. Viral infection of CFs and cardiomyocytes induces IFN- $\beta$ expression (55). In addition, stimulation of mouse CFs with the TLR3 agonist poly I:C induces Ifnb1 mRNA and CXCL10 protein expression (40). Our $\mathrm{BM}$ transplantation experiments indicated that PAR-1 on nonhematopoietic cells plays a role in CVB3-induced myocarditis. Although CFs and cardiomyocytes both express PAR-1 (35), CFs are easier than cardiomyocytes to isolate and maintain in culture. Therefore, we examined the effect of PAR-1 activation on poly I:C induction of Ifnb1 mRNA and CXCL10 expression in $\mathrm{Parl}^{1^{++}} \mathrm{CFs}$. Time course experiments showed that poly I:C stimulation led to maximal Ifnb1 mRNA expression at 2 hours and maximal CXCL10 protein expression at 8 hours (data not shown). TLR3 is generally present in endosomes, but can also be expressed on the cell surface (39). To confirm that TLR3 was mediating the induction of CXCL10 expression, we used various inhibitors of TLR 3 signaling. Clathrin-dependent endocytotic uptake of poly I:C was inhibited with monodansylcadaverine (MDC; $60 \mu \mathrm{M})$, endosomal acidification was inhibited with chloroquine $(100 \mu \mathrm{M})$, and TBK-1 activation was inhibited with BX795 $(1 \mu \mathrm{M})$. All 3 inhibitors reduced poly I:C induction of CXCL10 in WT CFs by $70 \%-100 \%$ (data not shown). Taken together, these results indicated that poly I:C induction of CXCL10 is primarily mediated by TLR3.

Previous studies have shown that stimulation of PAR- 1 activates p38 (32). Furthermore, p38 is required for dsRNA-dependent induction of CXCL10 (68). Therefore, we analyzed the activation of p38 in CFs treated with poly I:C and/or a PAR-1 agonist peptide. We found that activation of PAR- 1 in $\mathrm{Parl}^{1^{++}} \mathrm{CFs}$ led to a small but significant transient phosphorylation of p38 between 15 and 60 minutes (Figure 8A). As expected, no response was observed in $\mathrm{Parl}^{-/-} \mathrm{CF}$. Stimulation of $\mathrm{Parl}^{+/+}$or $\mathrm{Parl}^{-/-}$cells with poly I:C led to slower phosphorylation of p38, with the highest levels at 120 minutes, but no significant differences were observed between $\mathrm{Parl}^{+/+}$and $\mathrm{Parl}^{-/-} \mathrm{CFs}$ (Figure 8A). Importantly, we observed a significant difference in the level of p38 phosphorylation between $\mathrm{Parl}^{+/+}$and $\mathrm{Parl}^{-/-}$CFs stimulated with poly I:C and agonist peptide (Figure 8A). In addition, there was a significant difference in p38 phosphorylation in $\mathrm{Parl}^{+/+}$cells treated with poly I:C alone
A

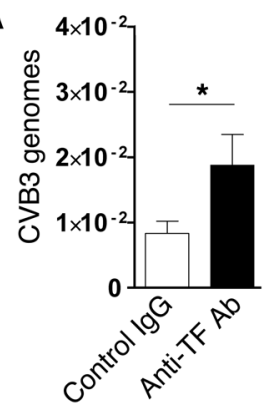

E

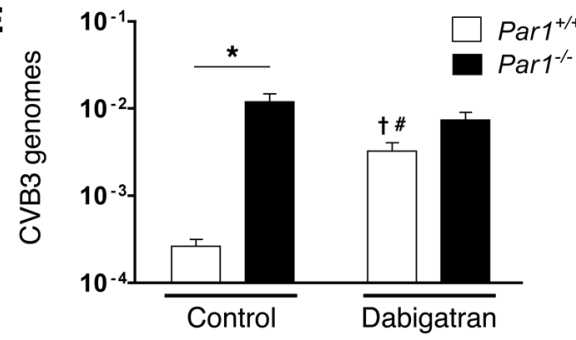

B

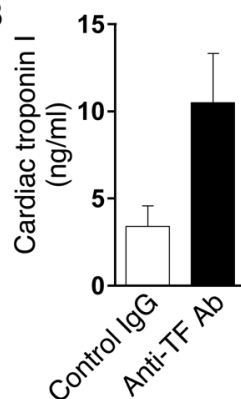

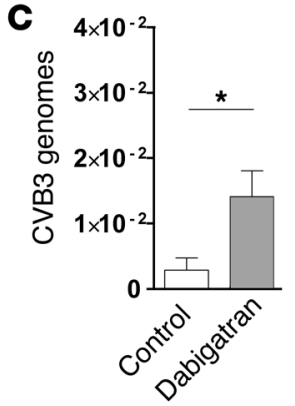
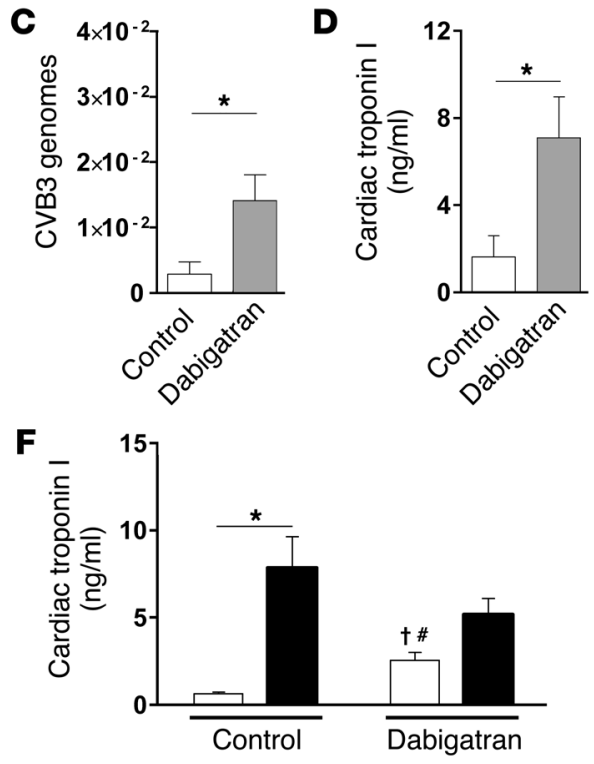

\section{Figure 7}

Effect of inhibition of TF or thrombin on CVB3-induced myocarditis. (A-D) TF inhibition ( $\mathbf{A}$ and $\mathbf{B}$ ) and thrombin inhibition ( $\mathbf{C}$ and $\mathbf{D})$ both increased levels of CVB3 genomes ( $\mathbf{A}$ and $\mathbf{C}$ ) and cardiac injury (B and $\mathbf{D})$ in WT mice at 8 dpi. Data (mean \pm SEM; $n=4-10$ per group) were analyzed by 2-tailed Student's $t$ test. ( $\mathbf{E}$ and $\mathbf{F}$ ) Thrombin inhibition increased CVB3 genomes and cardiac injury in Par1+/+ mice (white bars), but reduced CVB3 genomes and cardiac injury in $\mathrm{Par1}^{-/-}$mice (black bars). Data (mean \pm SEM; $n=10-23$ per group) were analyzed by 2-way ANOVA. ${ }^{*} P<0.05$; ${ }^{\#} P<0.05$ vs. $P$ ar $1^{+/+}$ control; ${ }^{\dagger} P<0.05$ vs. $P$ ar1 $1^{-/-}$control. 
A

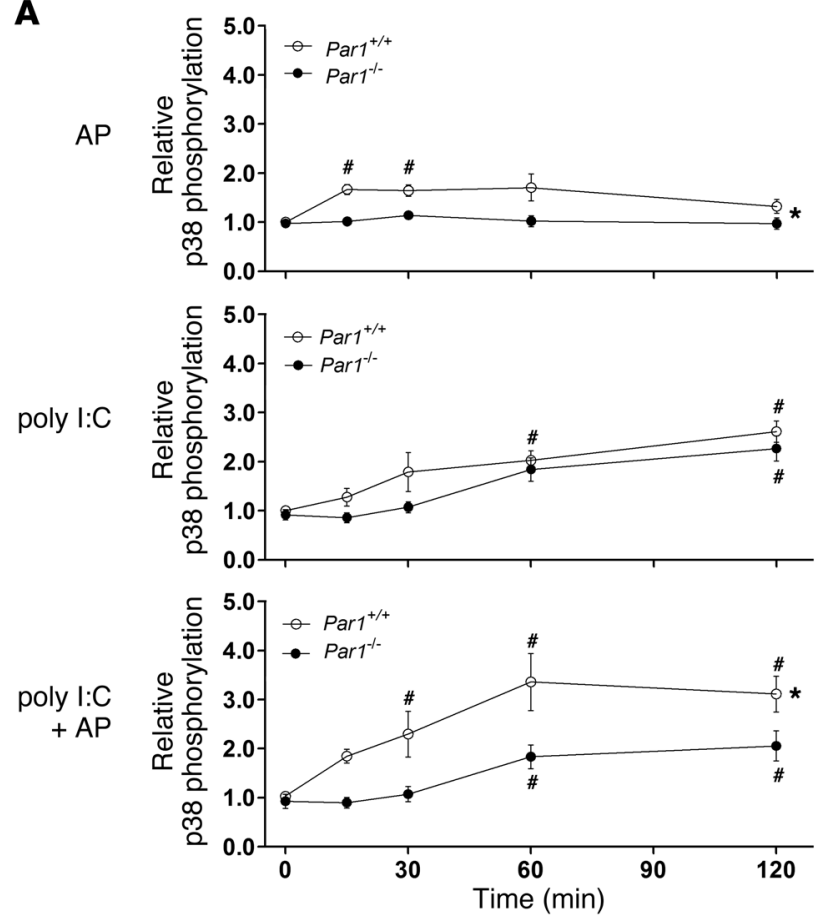

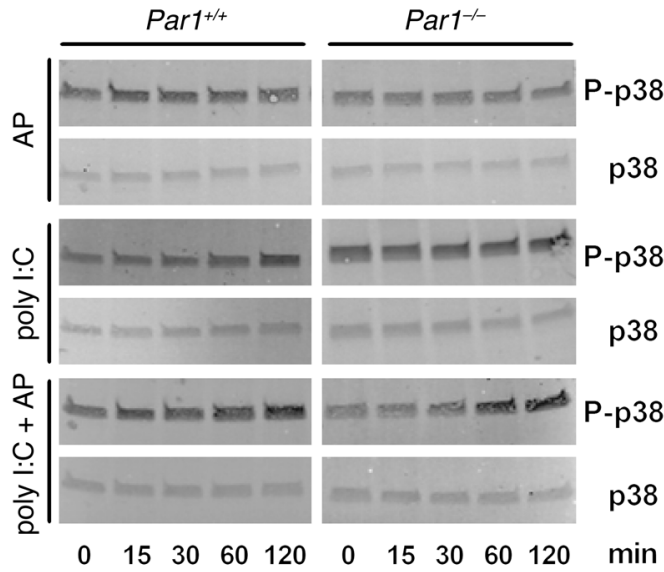

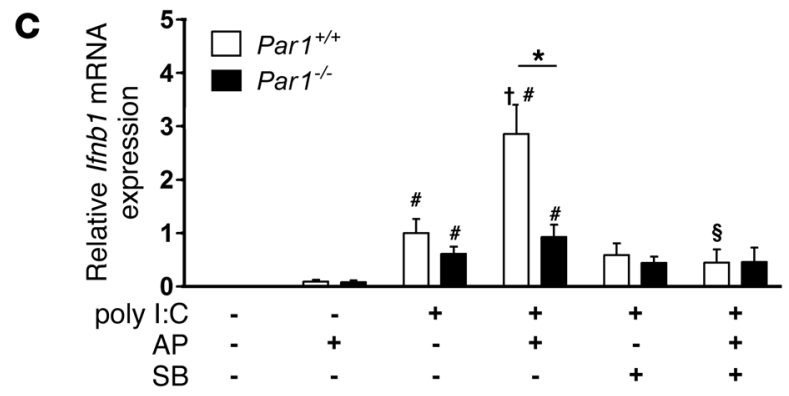

p38

\section{3}
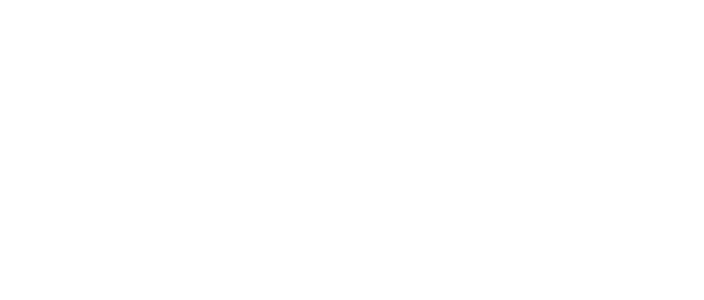

B

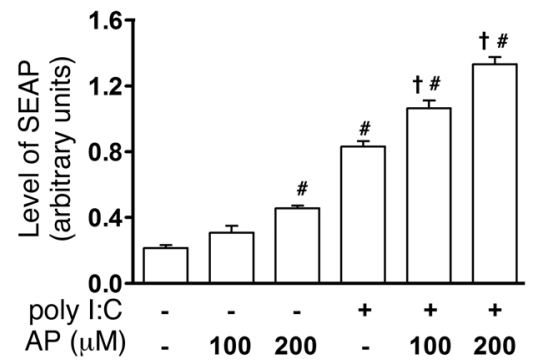

(n)


A

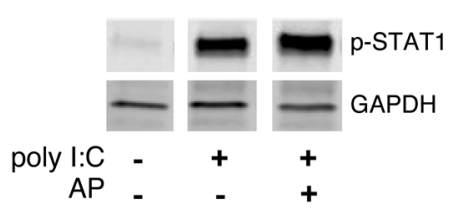

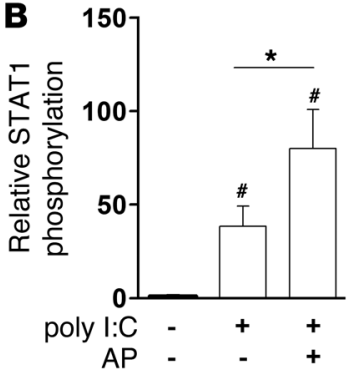

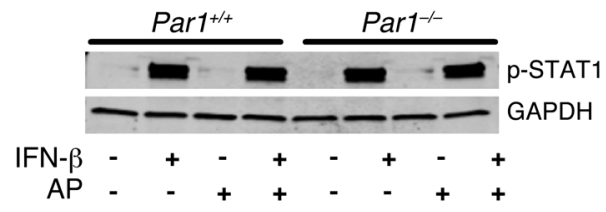

D

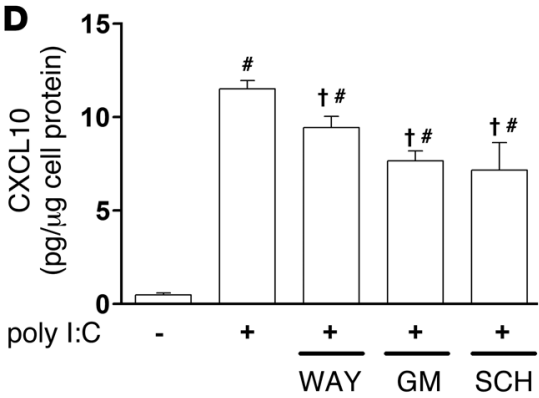

\section{Figure 9}

Effect of PAR-1 activation on poly I:C activation of STAT1 and CXCL10 expression. (A) Levels of phosphorylated STAT1 in unstimulated or stimulated $(25 \mu \mathrm{g} / \mathrm{ml}$ poly I:C with or without $200 \mu \mathrm{M}$ agonist peptide for 2 hours) Par1+/+ CFs. STAT1 phosphorylation levels (normalized to GAPDH) are shown relative to unstimulated $P a r 1^{+/+}$. (B) STAT1 phosphorylation in $P a r 1^{+/+}$and $P a r 1^{-/-}$CFs treated with $125 \mathrm{ng} / \mathrm{ml} \mathrm{recombinant} \mathrm{IFN-} \beta$ with or without $200 \mu \mathrm{M}$ agonist peptide for 30 minutes. (C) CXCL10 expression in Par1 ${ }^{+/+}$(white bars) and Par1 $1^{-/-}$(black bars) CFs stimulated with $25 \mu \mathrm{g} / \mathrm{ml}$ poly I:C with or without $200 \mu \mathrm{M}$ agonist peptide for 8 hours. $10 \mu \mathrm{M}$ SB203580 was added 30 minutes prior to poly I:C stimulation. (D) Effect of MMP or PAR-1 inhibition during poly I:C stimulation of Par1+/+ CFs. The pan-MMP inhibitor GM6001 (GM; $1 \mu \mathrm{M})$, the MMP13 inhibitor WAY170523 (WAY; $1 \mu \mathrm{M})$, or the PAR-1 antagonist SCH79797 (SCH; $250 \mathrm{nM}$ ) were added 30 minutes prior to poly I:C stimulation. Data (mean \pm SEM; $n=3-9$ independent experiments) were analyzed by 1-way (A and D) or 2-way (C) ANOVA. ${ }^{*} P<0.05$; ${ }^{\#}<0.05$ vs. unstimulated control within the same genotype; ${ }^{\dagger} P<0.05$ versus poly $\mathrm{I}: \mathrm{C}$ alone within the same genotype.

MEK1/2 with $10 \mu \mathrm{M}$ PD98059 (69) had no effect on the induction of Ifnb1 mRNA with poly I:C alone or with agonist peptide (data not shown). These results indicated that $\mathrm{p} 38$ activation is required for both poly I:C induction of CXCL10 and agonist peptidedependent enhancement of Ifnb1 mRNA expression.

IFN- $\beta$ binds to the type I IFN receptor on fibroblasts and induces CXCL10 expression via activation of the transcription factor STAT1 (70). As expected from the results with Ifnb1 mRNA expression, $\mathrm{Parl}^{+/+}$cells costimulated with both poly I:C and agonist peptide expressed higher levels of phosphorylated STAT1 than did $\mathrm{Parl}^{+/+}$ cells stimulated with poly I:C alone (Figure 9A), which indicates that the costimulated cells released more IFN- $\beta$. Similar results were observed with adult mouse $\mathrm{Par}^{+/+} \mathrm{CFs}$ (data not shown). To confirm that there was no defect in IFN- $\beta$ signaling in $\mathrm{Parl}^{-/-} \mathrm{CFs}$, we compared the level of phosphorylated STAT1 in $\mathrm{Parl}^{+/+}$and $\mathrm{Parl}^{-/-}$ CFs stimulated with recombinant IFN- $\beta$. We found that recombinant IFN- $\beta$ induced a similar level of STAT1 phosphorylation at 30 minutes in $\mathrm{Parl}^{+/+}$and $\mathrm{Parl}^{-/-} \mathrm{CF}$ and that the phosphorylation was not increased by agonist peptide (Figure $9 \mathrm{~B}$ ). These results indicated that $\mathrm{Parl}^{-/-}$CFs have a deficiency in the induction of Ifnb1 mRNA expression, but not in IFN receptor signaling.

Poly I:C stimulation of $\mathrm{Parl}^{+/+}$and $\mathrm{Parl}^{-/-}$CFs induced CXCL10 expression, and this was significantly enhanced in $\mathrm{Parl}^{+/+} \mathrm{CFs}$, but not $\mathrm{Parl}^{-/-}$CFs, by activation of PAR-1 (Figure 9C). CXCL10 expression was also significantly reduced by inhibition of p38 (Figure 9C). Interestingly, poly I:C-stimulated $\mathrm{Parl}^{-/-} \mathrm{CF}$ expressed less CXCL10 at 8 hours compared with poly I:C-treated $\mathrm{Par}^{+/+} \mathrm{CFs}$
(Figure 9C). We recently showed that stimulation of $\mathrm{Parl}^{+/+} \mathrm{CFs}$ with isoproterenol induced the release of MMPs that activate PAR-1 (71). Therefore, we examined whether MMP activation of PAR-1 increases CXCL10 induction in $\mathrm{Parl}^{+/+}$CFs stimulated with poly I:C. $\mathrm{Parl}^{+/+} \mathrm{CF}$ s were stimulated with poly I:C in the absence or presence of the MMP13 inhibitor WAY170523, the pan-MMP inhibitor GM6001, or the PAR-1 antagonist SCH79797. Blockade of MMPs or PAR-1 significantly reduced poly I:C induction of CXCL10 (Figure 9D). These results indicate that poly I:C-stimulated CFs release MMPs that activate PAR-1, which enhances CXCL10 expression.

PAR-1 deficiency is associated with increased viral load and inflammation after influenza A infection. Recent studies have shown that influenza A infections lead to a TLR3-dependent innate immune response, activation of coagulation, and an increase in PAR-1 expression in the lung $(72,73)$. To determine whether PAR-1 plays a role in the innate immune response to a different virus, we examined the effect of PAR-1 deficiency on infection with the ssRNA virus HA type 1 and neuraminidase type 1/Puerto Rico strain 8/34 (H1N1/ PR8) influenza A. Mice were infected i.n. with $50 \mu$ l of 2 hemagglutinating units of $\mathrm{H} 1 \mathrm{~N} 1 / \mathrm{PR} 8$ virus diluted in PBS. We found that $\mathrm{Par1}^{-/-}$mice expressed lower levels of lung CXCL10 and higher levels of H1N1/PR8 viral genomes compared with $\mathrm{Parl}^{+/+}$mice at $3 \mathrm{dpi}$ (Figure 10, A and B). Furthermore, at $3 \mathrm{dpi}$, $\mathrm{Par1}^{-/-}$mice had higher levels of proinflammatory cytokines and chemokines in the BAL fluid than did $\mathrm{Parl}^{+/+}$mice (Figure 10, C-F). These results suggest that PAR-1 also plays a role in the innate immune response to influenza A infection. 

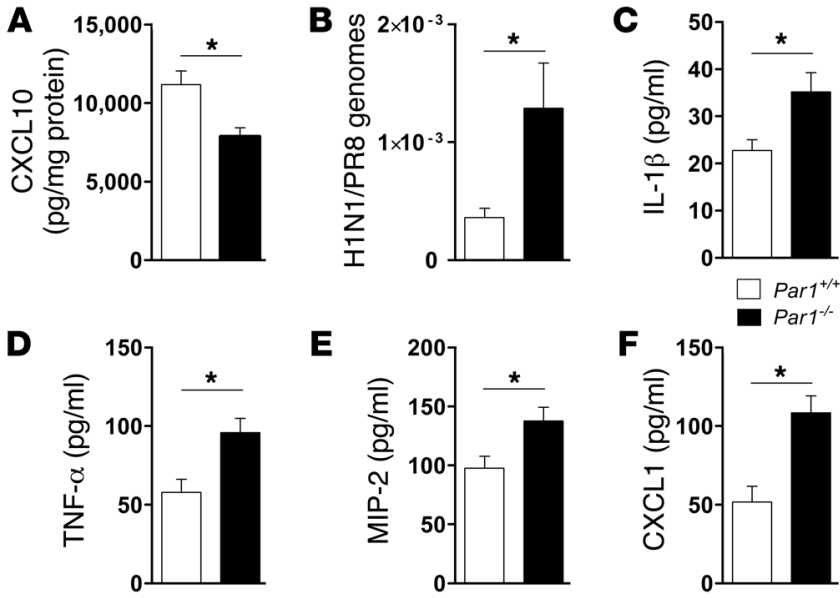

E

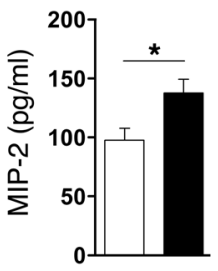

F

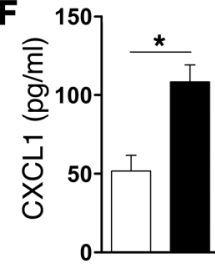

Figure 10

Role of PAR-1 in influenza A infection. Levels of CXCL10 protein (A) and $\mathrm{H} 1 \mathrm{N1/PR} 8$ genomes (B) in the lungs and of inflammatory mediators in BAL $(\mathbf{C}-\mathbf{F})$ of H1N1/PR8 influenza A-infected Par1/++ (white bars) and Par1 $^{-1-}$ (black bars) mice at 3 dpi. Data are mean \pm SEM $(n=5-6) .{ }^{*} P<0.05$, 2-tailed Student's $t$ test.

\section{Discussion}

In this study, we found that $\mathrm{Par}^{1^{-/}}$mice were more susceptible to infection with the ssRNA viruses CVB3 and influenza A compared with $\mathrm{Parl}^{+/+}$mice. Par1 $1^{-/-}$mice exhibited reduced IFN- $\beta$ and CXCL10 expression in the heart early after CVB3 infection, which likely explains the increased viral load in the heart at $8 \mathrm{dpi}$. The higher amount of CVB3 virus in $\mathrm{Par1}^{-/-}$mice was associated with increased levels of inflammatory cells, increased expression of cytokine mRNAs, and increased cardiac injury compared with $\mathrm{Parl}^{+/+}$mice. Although $\mathrm{Parl}^{-/-}$mice had higher levels of virus during the acute phase of CVB3 infection, they were able to eliminate the virus by $28 \mathrm{dpi}$, which indicates that they had a normal adaptive immune response. Our results are consistent with a prior study showing that TLR3 deficiency reduces the innate immune response to CVB3 infection without affecting the adaptive immune response (74). We also found that $\mathrm{Parl}^{-/-}$mice had reduced CXCL10 expression in the lung after $\mathrm{H} 1 \mathrm{~N} 1 / \mathrm{PR} 8$ infection, which was associated with increased amounts of virus and expression of inflammatory mediators compared with infected $\mathrm{Parl}^{+/+}$mice. These results indicate that PAR-1 plays a role in the innate immune response to 2 different ssRNA viruses.

In viral myocarditis, NK cells infiltrate the heart first and limit viral replication (75). $\mathrm{Tlr}^{-1-}$ and Trif ${ }^{--}$mice both exhibited less inflammatory cell infiltrates in their hearts at $3 \mathrm{dpi}(48,76)$. In a heart transplantation model, PAR-1 deficiency was associated with reduced recruitment of NK cells and immune cells into the heart (77). Consistent with this observation, we found reduced levels of Nk1.1 mRNA expression, which is expressed by NK cells, in the hearts of $\mathrm{Parl}^{-/-}$mice after CVB3 infection compared with $\mathrm{Parl}^{+/+}$ controls. These results suggest that the increased viral titers in the hearts of $\mathrm{Parl}^{-/-}$mice is due to a defect in early expression of the IFN- $\beta / C X C L 10$ antiviral pathway and the recruitment of NK cells. Thrombin stimulation of NK cells has been shown to increase their cell-mediated cytotoxicity (78). Consistent with this observation, we found that a PAR-1 agonist peptide increased the cyto- toxic activity of $\mathrm{Parl}^{+/+} \mathrm{NK}$ cells, but not $\mathrm{Par1}^{-/-} \mathrm{NK}$ cells, within the splenocyte population (data not shown). This result indicates that PAR-1 also contributes to the cytotoxicity of NK cells.

BM transplantation experiments revealed that nonhematopoietic cells were the major source of PAR-1 contributing to the antiviral response after CVB3 infection. Furthermore, mice with cardiomyocyte-specific overexpression of PAR-1 were protected against CVB3 infection compared with WT littermate controls. In vitro experiments with CFs showed that activation of PAR-1 enhanced poly I:C activation of $\mathrm{p} 38$ and expression of IFN- $\beta$ and CXCL10. Consistent with a role for p38 in the expression of the IFN- $\beta$ /CXCL10 pathway, we found that inhibition of p38 reduced induction of both Ifnb1 mRNA and CXCL10 in CFs stimulated with both agonist peptide and poly I:C. Taken together, our results indicate that PAR-1 contributes to the expression of antiviral genes in CFs and that there is cooperative signaling between PAR-1 and TLR3. This supports the notion of a dual-sensor system, in which an infection is detected by TLRs recognizing PAMPs and PARs being activated by proteases generated by the clotting cascade and other systems (58). Interestingly, we have observed substantially reduced CVB3-induced myocarditis in Par2 ${ }^{-/-}$compared with WT mice (A. Weithäuser, S. Antoniak, N. Mackman, and U. Rauch, unpublished observations). These results indicate that there are specific interactions between different PARs and TLRs in response to CVB3 infection.

Viral infections induce TF expression and activate coagulation (12-15). Previously, we found that CVB3 infection of mice increased TF protein expression in the heart and increased fibrin deposition (14). In addition, the TLR3 agonist poly I:C has been shown to induce TF expression in endothelial cells and activate coagulation in mice (17). In this study, we observed an increase in the levels of $T f$ mRNA in the liver and heart, as well as TAT complexes in the plasma, at $8 \mathrm{dpi}$. Fibrin was deposited in areas of the myocardium adjacent to inflammatory cell infiltrates. Importantly, we also found that inhibition of either TF or thrombin in WT mice increased CVB3-induced myocarditis. These results suggest that virus activation of the $\mathrm{TF} /$ thrombin/PAR-1 pathway contributes to activation of the innate immune system. Surprisingly, inhibition of thrombin in $\mathrm{Par1}^{-/-}$mice decreased levels of CVB3 virus and cardiac injury. One possible explanation for these results is that coating of virally infected cells with fibrin may interfere with the clearance of these cells by NK cells. Indeed, fibrin has previously been shown to increase the metastasis of tumor cells by impeding NK cell killing (79).

It is notable that a deficiency of PAR-1 was associated with significantly higher levels of CVB3-induced myocarditis compared with either TF or thrombin inhibition in WT mice. This suggests that there may be other protease activators of PAR-1 that are generated during CVB3 infection. MMPs represent likely candidates. Several studies showed that the MMPs are required for early virus clearance in myocarditis (80). For example, a deficiency of MMP9 was associated with increased CVB3 virus load and inflammation at 9 dpi due to early impaired innate immune response (81). Our in vitro studies revealed that poly I:C stimulation of $\mathrm{Par1}^{-/-}$CFs produced less CXCL10 than $\mathrm{Parl}^{+/+}$cells. We found that poly I:C-stimulated mouse CFs released MMPs that activated PAR-1 and increased CXCL10 expression. This is consistent with our recent study showing that isoproterenol-stimulated rat CFs express MMPs that activate PAR-1 (71). Furthermore, we found that administration of the MMP13 inhibitor 
WAY170523 (7.5 mg/kg i.p.) once daily significantly increased levels of CVB3 in the hearts of WT mice compared with levels in mice receiving vehicle $(0.0238 \pm 0.0054$ versus $0.0076 \pm 0.0023$ CVB3 genomes normalized to $18 \mathrm{~S}$ rRNA; $n=6-10 ; P<0.05)$. Therefore, both thrombin and MMPs may activate PAR- 1 in the heart during CVB3 infection.

Our results revealed an unexpected protective role for the TF/ thrombin/PAR-1 pathway during infection of mice with 2 ssRNA viruses. Clinically, the direct thrombin inhibitor dabigatran etexilate (Pradaxa) is approved for the prevention of blood clots and stroke in patients with atrial fibrillation (82), and a selective PAR-1 inhibitor, vorapaxar, has been developed as a novel antiplatelet drug $(83,84)$. To date, there are no reports of increased rates of viral infection in patients receiving Pradaxa (http://www. pradaxapro.com/safety.jsp) or in patients receiving vorapaxar (83, 84). Nevertheless, our study raises the possibility that inhibitors of thrombin or PAR-1 may increase the risk and severity of viral infection in patients.

\section{Methods}

Materials. The following cell culture grade reagents were used: poly I:C (Sigma-Aldrich); PAR-1 agonist peptide (TFLLR-NH2; Abgent); recombinant murine IFN- $\beta$ (ProSpec); MDC (Sigma-Aldrich); chloroquine (Invivogen); BX795 (Invivogen); PD98059 (Cell Signaling); SB203580 (Cell Signaling). The pan-MMP inhibitor GM6001 was purchased from Calbiochem (71). The specific MMP13 inhibitor WAY170523 and the PAR-1 antagonist SCH79797 were purchased from Tocris Bioscience (71). For Western blot analysis, we used specific antibodies against phosphorylated p38 and total p38 (Cell Signaling), phosphorylated STAT1 (Abcam), and GAPDH (Santa Cruz Biotechnology).

Mice. Par1 ${ }^{+/+}$and $\mathrm{Par1}^{-/-}$mice were backcrossed 11 generations onto a C57BL/6J background, and then $\mathrm{Parl}^{1^{+/}}$and $\mathrm{Par1}^{-/-}$lines were generated and maintained by cousin breeding (85). Male mice were used for all experiments. $\alpha$ MHCPAR- 1 mice on a C57BL/6J background overexpress PAR-1 on cardiomyocytes from the $\alpha \mathrm{MHC}$ promoter and have been described previously (36).

Virus infection. CVB3 was from the cardiotropic Nancy strain. Virus stocks were isolated as described previously (86). Mice were infected at 6-8 weeks of age i.p. Whereas $10 \%$ of $\mathrm{Parl}^{-/-}$mice died after infection, none of the $\mathrm{Parl}^{+/+}$mice died. We used the mouse-adapted strain of influenza A (H1N1/PR8; ATCC). The virus was propagated in the allantoic fluid of 10-day-old fertilized hen eggs, and viral titer was determined by hemagglutination assay (87). For virus inoculation, mice were anesthetized with an i.p. injection of a ketamine/xylazine solution $(0.6$ and $0.35 \mathrm{mg} / \mathrm{kg}$, respectively) and infected i.n. with H1N1/PR8. Previous studies determined that this dose of virus is sufficient to elicit an immune response in mice (87).

Quantification of CVB3 titers. HeLa cells (Wisconsin strain; provided by R. Rueckert, University of Wisconsin-Madison, Madison, Wisconsin, USA) were plated in 96-well plates. Weighed heart samples were homogenized in minimum essential media, frozen and thawed 5 times, and centrifuged at $9,300 \mathrm{~g}$ for 10 minutes at $4^{\circ} \mathrm{C}$. The supernatant was collected and filtered. Serial 10-fold dilutions of the supernatant were added to HeLa cell plates in replicates of 6 . Virus titers were determined by counting plaques after 2-3 days of incubation (48).

Histology. Hearts were either snap frozen and embedded in Tissue-Tek OCT compound (Dako) or fixed in 4\% PFA and embedded in paraffin (Sigma-Aldrich). Sections from paraffin-embedded tissues were stained with H\&E. Tissue-Tek- or paraffin-embedded sections were washed with PBS, treated with $4 \% \mathrm{H}_{2} \mathrm{O}_{2}$, and incubated in a humidified chamber with primary antibodies against CD3 (1:75; Santa Cruz Biotechnologies), CD68
(1:500; Abcam), or fibrin(ogen) (59D8, 1:1,000; gift of M. Runge, University of North Carolina at Chapel Hill, Chapel Hill, North Carolina, USA). Slides were then washed, incubated with the appropriate biotinylated secondary antibody (Dako), and counterstained with hematoxylin (Merck). The Vecastatin ABC Kit (Vector Laboratories) was used to detect the biotintagged secondary antibody (14). Images were taken with a 3CCD Donpisha Color Vision Camera attached to a Leica DM RBE microscope (original magnification, $\times 200$; Leica Microsystems), and staining was quantified with Lucia software (Bensheim).

Echocardiology. Echocardiography was performed using a VisualSonics Vevo 660 ultrasound system as described previously (88). LV and LV wall dimensions at the end of systole and diastole were measured digitally on M-mode tracings and averaged from 4 cardiac cycles. FS was calculated from measured ventricle dimensions (36).

Measurement of plasma cardiac troponin I and TAT complexes. Blood was collected from the inferior vena cava into the anticoagulant sodium citrate (final concentration, $0.38 \%$ ) and centrifuged $(4,500 \mathrm{~g}$ for 15 minutes at $4^{\circ} \mathrm{C}$ ) to obtain plasma, which was stored at $-80^{\circ} \mathrm{C}$ until analysis. Cardiac injury was assessed by measuring plasma levels of cardiac troponin I from control and infected mice using a highly sensitive mouse cardiac troponin I ELISA kit (Life Diagnostics). Plasma TAT levels were quantified by ELISA (TAT Enzygnost Micro Kit; Dade Behring/Siemens).

Measurement of CVB3 and influenza A genomes and cytokine $m R N A$ levels in tissues. Total RNA was prepared from heart, liver, and lung and reverse transcribed into cDNA as previously described (88). Levels of different mRNAs were analyzed by real-time PCR using iTaq Fast Supermix (Bio-Rad) and realplex ${ }^{2}$ Mastercycler (Eppendorf AG). Amplification of $18 \mathrm{~S}$ rRNA was used to correct for input RNA level variation and reaction efficiency. Levels of different mRNAs were measured using the following TaqMan probe sets from Applied Biosystems: 18S (4310893E); Illb (Mm01336189_m1); Il6 (Mm99999064_m1); Ifnb1 (Mm00439552_s1); Tnfa (Mm00443259_g1); Par1 (Mm00438851_m1). For detection of Nk1.1 mRNA and of CVB3 and H1N1/PR8 genomes, we used the following probe sets from Integrated DNA Technologies: Nk1.1 forward, 5'-ACTAAACCATGAAACCCCGAG-3'; Nk1.1 reverse, 5'-AGTGCTTTCAGAGTCCATGTG-3'; Nk1.1 probe, 5'-FAM-ACTCCTGACTGCGAATCCCATCC-TAMRA-3'; CVB3 forward, 5'-CCCTGAATGCGGCTAATCC-3'; CVB3 reverse, 5'-ATTGTCACCATAAGCAGCCA-3'; CVB3 probe, 5'-FAM-TGCAGCGGAACCG-TAMRA-3'; H1N1/ PR8 forward, 5'-GGACTGCAGCGTAGACGCTT-3'; H1N1/PR8 reverse, 5'-CATCCTGTTGTATATGAGGCCCAT-3'; H1N1/PR8 probe, 5'-FAMCTCAGTTATTCTGCTGGTGCACTTGCCA-TAMRA-3'.

Measurement of cytokines and chemokines. Tissue samples were generated and BAL fluid collected as described previously $(14,89)$. Protein concentrations of TNF- $\alpha$, IL-1 $\beta$, CXCL1, macrophage-inflammatory protein-2 (MIP-2), and CXCL10 were measured using commercial ELISAs (Duo-Set; R\&D Systems).

BM transplantation. Recipient mice (4 weeks old) were irradiated with 13 Gy (2 doses of 6.5 Gy, 4 hours apart) using a cesium 137 irradiator (JL Shepherd) to ablate endogenous BM-derived cells. Irradiated mice were injected via the retro-orbital sinus with $2 \times 10^{6} \mathrm{BM}$ cells isolated from donor animals as described previously (90). Mice were allowed to recover for 4 weeks before CVB3 infection.

Isolation of embryonic CFs. Hearts of $\mathrm{Parl}^{+/+}$or $\mathrm{Par1}^{-/-}$embryos (E14) were aseptically isolated and digested overnight in $0.05 \%$ trypsin/EDTA (Sigma-Aldrich). The next day, digested heart tissue was resuspended and plated in DMEM-H media (Gibco) containing 10\% FBS, 1\% penicillin/streptomycin, and L-glutamine (Cellgro) for 2 hours to allow for adherence of fibroblasts (91). Nonadherent cells were discarded, and the enriched fibroblast population was cultured for 7 days. CFs were plat- 
ed into wells of a 24 -well plate $\left(1.5 \times 10^{5}\right.$ cells/well $)$ and stimulated the next day in serum-free media with poly I:C $(25 \mu \mathrm{g} / \mathrm{ml})$, IFN- $\beta(125 \mathrm{ng} /$ $\mathrm{ml})$, and/or agonist peptide $(200 \mu \mathrm{M})$. We observed reduced numbers of $\mathrm{Par1}^{-/-}$cells compared with $\mathrm{Parl}^{+/+}$cells, which may be due to reduced growth (34). TLR3 signaling was inhibited by incubating cells with MDC $(60 \mu \mathrm{M})$, chloroquine $(100 \mu \mathrm{M})$, or BX795 $(1 \mu \mathrm{M})(41,92,93)$. Cells were also preincubated for 30 minutes with PD98059 $(10 \mu \mathrm{M})$ or SB203580 $(10 \mu \mathrm{M})$ to inhibit activation of MEK1 or p38 MAPKs, respectively (69). To inhibit MMP activity or PAR-1, WT cells were incubated 30 minutes prior poly I:C stimulation with GM6001 (1 $\mu \mathrm{M})$, WAY170523 (1 $\mu \mathrm{M})$, or SCH79797 (250 nM) (71).

HEK-293 transfection studies. HEK-293 cells transfected with a stable human TLR3-HA tag (pUNO-hTLR3-HA plasmid; Invivogen) were grown to $70 \%$ confluence and transfected with a pNiFty2-IFB-SEAP plasmid (containing the Ifnb1 promoter) with Zeocin selection (Invivogen) using Lipofectamine 2000 (Invitrogen). Briefly, cells were cotransfected under antibiotic-free conditions in 12-well plates for 6 hours and then washed, after which growth media was added. After 24 hours, cells were selected using Zeocin (100 $\mu \mathrm{g} / \mathrm{ml}$; Invivogen) for an additional 24 hours. Cells were washed and then incubated with fresh growth media, either alone or with agonist peptide (100 or $200 \mu \mathrm{M})$ and/or poly I:C $(25 \mu \mathrm{g} / \mathrm{ml})$, for an additional 24 hours. Media was collected, and SEAP was detected using QUANTI-blue (Invivogen), black well plates, and a SpectraMax M5 plate reader $(640 \mathrm{~nm})$.

Western blot analysis. Cell lysates were resuspended in $6 \times$ Laemmli sample buffer, boiled for 5 minutes, and then applied to $4 \%-15 \%$ Tris-Glycine gels (Bio-Rad Laboratories) to separate proteins using electrophoresis. Proteins were transferred to PVDF membranes (Millipore), and membranes were blocked for 1 hour with Odyssey blocking buffer (LI-COR Biosciences). Primary antibodies against phosphorylated p38 (1:1,000 dilution), nonphosphorylated p38 (1:1,000 dilution), phosphorylated STAT1 (1:1,000 dilution), and GAPDH (1:10,000 dilution) were incubated overnight at $4^{\circ} \mathrm{C}$. Washed membranes were incubated with fluorescence-labeled secondary antibodies (1:10,000 dilution) for 1 hour. Membranes were then washed 3 times and analyzed using an Odyssey Infrared Imaging System (LI-COR Biosciences).

Inbibition of TF, thrombin, or MMP13 in mice. For inhibition of TF, WT mice received i.p. injections of the rat anti-mouse TF monoclonal antibody $1 \mathrm{H} 1(20 \mathrm{mg} / \mathrm{kg}$ ) or an isotype control (rat IgG2a, $20 \mathrm{mg} / \mathrm{kg}$; Sigma-Aldrich) (90). For inhibition of thrombin, WT mice were fed custom-made AIN-93M chow diets containing peanut flavoring $(2 \mathrm{~g} / \mathrm{kg}$ chow) with or without dabigatran etexilate (10 g/ kg chow) (Dyets Inc.). $30 \%$ of mice treated with dabigatran etexilate exhibited signs of gastrointestinal bleeding, and death rates for $\mathrm{Parl}^{1^{+/}}$and $\mathrm{Parr}^{-/-}$mice were $10 \%$ and $30 \%$, respectively. aPTT was measured using the Actin FS kit (Dade
Behring/Siemens) on a Start 4 machine (Diagnostica Stago). For inhibition of MMP13, WT mice were injected i.p. with the MMP13 inhibitor WAY170523 $(7.5 \mathrm{mg} / \mathrm{kg})$ once daily (71).

Statistics. All statistical analyses were performed using GraphPad Prism (version 5.0; GraphPad Software Inc.) or SAS (version 9.2; SAS). Data are represented as mean \pm SEM. For 2-group comparison of continuous data, 2 -tailed Student's $t$ test was used. For multiple-group comparison, normally distributed data were analyzed by 1- or 2-way ANOVA and were Bonferroni corrected for repeated measures over time. A $P$ value less than 0.05 was considered significant. Linear mixed models with a random intercept were used to determine whether significant differences exist between p38 phosphorylation in stimulated $\mathrm{Parl}^{1^{+/+}}$and $\mathrm{Parl}^{1^{-/}}$CFs over time. The $P$ value for the group effect was calculated using a likelihood ratio test.

Study approval. All mouse studies were performed in accordance with the guidelines of the IACUC of UNC-Chapel Hill and complied with NIH guidelines.

Note added in proof. After the completion of this work, Khoufache and colleagues reported that PAR1 contributed to inflammation after infection of mice with H1N1 (94). The majority of these studies used an agonist peptide to stimulate PAR1 and an antagonist to inhibit PAR1 in WT mice. However, the authors also found that $\mathrm{Par}^{-1-}$ mice were protected from virus infection compared with WT mice. These results contrast with our studies showing that $\mathrm{Parl}^{-/-}$mice exhibited more inflammation that WT mice after infection with H1N1. Additional studies are required to resolve these differences, and it seems premature to propose the use of PAR1 antagonists for the treatment of influenza.

\section{Acknowledgments}

We thank Franziska Bleis, Kerstin Kamprath, and Ying Zhang for excellent technical assistance; Maria Aleman for advice on fibrin(ogen) staining; and Alisa Wolberg and Julia Gambone for reading the manuscript. This study was supported by grants from the Myocarditis Foundation (to S. Antoniak), the DFG (SFB-TR19 A3; to U. Rauch), and the NIH (HL084087; to N. Mackman, R. Pawlinski, and B.C. Blaxall).

Received for publication August 1, 2012, and accepted in revised form December 10, 2012.

Address correspondence to: Nigel Mackman, University of North Carolina at Chapel Hill, 98 Manning Drive Campus Box 7035, Chapel Hill, North Carolina 27599, USA. Phone: 919.843.3961; Fax: 919.966.7639; E-mail: nmackman@med.unc.edu.
1. Loof TG, et al. Coagulation, an ancestral serine protease cascade, exerts a novel function in early immune defense. Blood. 2011;118(9):2589-2598.

2. Sun $H$. The interaction between pathogens and the host coagulation system. Physiology (Bethesda). 2006;21:281-288.

3. Sun $\mathrm{H}$, et al. Plasminogen is a critical host pathogenicity factor for group A streptococcal infection. Science. 2004;305(5688):1283-1286.

4. Iwanaga S, Kawabata S. Evolution and phylogeny of defense molecules associated with innate immunity in horseshoe crab. Front Biosci. 1998;3:D973-D984.

5. Degen JL, Bugge TH, Goguen JD. Fibrin and fibrinolysis in infection and host defense. J Thromb Haemost. 2007;5(suppl 1):24-31.

6. Hoffmann JA. Innate immunity of insects. Curr Opin Immunol. 1995;7(1):4-10.

7. Mackman N, Tilley RE, Key NS. Role of the extrin- sic pathway of blood coagulation in hemostasis and thrombosis. Arterioscler Thromb Vasc Biol. 2007;27(8):1687-1693.

8. Coughlin SR. Thrombin signalling and proteaseactivated receptors. Nature. 2000;407(6801):258-264.

9. Antoniak S, Pawlinski R, Mackman N. Proteaseactivated receptors and myocardial infarction. IUBMB Life. 2011;63(6):383-389.

10. Soh UJ, Dores MR, Chen B, Trejo J. Signal transduction by protease-activated receptors. $\mathrm{Br} \mathrm{J}$ Pharmacol. 2010;160(2):191-203.

11. Osterud B, Flaegstad T. Increased tissue thromboplastin activity in monocytes of patients with meningococcal infection: related to an unfavourable prognosis. Thromb Haemost. 1983;49(1):5-7.

12. Key NS, et al. Infection of vascular endothelial cells with herpes simplex virus enhances tissue factor activity and reduces thrombomodulin expression.
Proc Natl Acad Sci U S A. 1990;87(18):7095-7099.

13. Geisbert TW, Young HA, Jahrling PB, Davis KJ, Kagan E, Hensley LE. Mechanisms underlying coagulation abnormalities in ebola hemorrhagic fever: overexpression of tissue factor in primate monocytes/macrophages is a key event. J Infect Dis. 2003;188(11):1618-1629.

14. Antoniak S, et al. Viral myocarditis and coagulopathy: increased tissue factor expression and plasma thrombogenicity. J Mol Cell Cardiol. 2008;45(1):118-126.

15. Funderburg NT, et al. Increased tissue factor expression on circulating monocytes in chronic HIV infection: relationship to in vivo coagulation and immune activation. Blood. 2010;115(2):161-167.

16. Huerta-Zepeda A, et al. Crosstalk between coagulation and inflammation during Dengue virus infection. Thromb Haemost. 2008;99(5):936-943.

17. Shibamiya A, et al. A key role for Toll-like recep- 
tor-3 in disrupting the hemostasis balance on endothelial cells. Blood. 2009;113(3):714-722.

18. Mackman N. Role of tissue factor in hemostasis, thrombosis, and vascular development. Arterioscler Thromb Vasc Biol. 2004;24(6):1015-1022.

19. Drake TA, Cheng J, Chang A, Taylor FB. Expression of tissue factor, thrombomodulin, and E-selectin in baboons with lethal Escherichia coli sepsis. Am J Pathol. 1993;142(5):1458-1470.

20. Morrissey JH, Drake TA. Procoagulant response of the endothelium and monocytes. In: Schlag C, RedI H, eds. Pathophysiology of Shock, Sepsis and Organ Failure. New York, New York, USA: Springer-Verlag Berlin; 1993:564-574.

21. Crossman DC, Carr DP, Tuddenham EG, Pearson JD, McVey JH. The regulation of tissue factor mRNA in human endothelial cells in response to endotoxin or phorbol ester. J Biol Chem. 1990; 265(17):9782-9787.

22. Gregory SA, Morrissey JH, Edgington TS. Regulation of tissue factor gene expression in the monocyte procoagulant response to endotoxin. Mol Cell Biol. 1989;9(6):2752-2755.

23. Brand K, Fowler BJ, Edgington TS, Mackman N. Tissue factor mRNA in THP-1 monocytic cells is regulated at both transcriptional and posttranscriptional levels in response to lipopolysaccharide. Mol Cell Biol. 1991;11(9):4732-4738.

24. Taylor FB, et al. Lethal E. coli septic shock is prevented by blocking tissue factor with monoclonal antibody. Circ Shock. 1991;33:127-134.

25. RufW. Emerging roles of tissue factor in viral hemorrhagic fever. Trends Immunol. 2004;25(9):461-464.

26. Levi M, et al. Inhibition of endotoxin-induced activation of coagulation and fibrinolysis by pentoxifylline or by a monoclonal anti-tissue factor antibody in chimpanzees. J Clin Invest. 1994;93(1):114-120.

27. Esmon CT, Xu J, Lupu F. Innate immunity and coagulation. JThromb Haemost. 2011;1:182-188.

28. Popovic M, Paskas S, Zivkovic M, Burysek L, Laumonnier Y. Human cytomegalovirus increases HUVEC sensitivity to thrombin and modulates expression of thrombin receptors. J Thromb Thrombolysis. 2010;30(2):164-171.

29. Sutherland MR, Friedman HM, Pryzdial EL. Thrombin enhances herpes simplex virus infection of cells involving protease-activated receptor 1 . J Thromb Haemost. 2007;5(5):1055-1061.

30. Sutherland MR, Ruf W, Pryzdial EL. Tissue factor and glycoprotein $\mathrm{C}$ on herpes simplex virus type 1 are protease-activated receptor 2 cofactors that enhance infection. Blood. 2012;119(15):3638-3645.

31. Coughlin SR. Protease-activated receptors in vascular biology. Thromb Haemost. 2001;86(1):298-307.

32. Cooper DM, Pechkovsky DV, Hackett TL, Knight DA, Granville DJ. Granzyme K activates proteaseactivated receptor-1. PLoS One. 2011;6(6):e21484.

33. Sabri A, et al. Signaling properties and functions of two distinct cardiomyocyte protease-activated receptors. Circ Res. 2000;86(10):1054-1061.

34. Sabri A, Short J, Guo J, Steinberg SF. Proteaseactivated receptor-1-mediated DNA synthesis in cardiac fibroblast is via epidermal growth factor receptor transactivation: distinct PAR-1 signaling pathways in cardiac fibroblasts and cardiomyocytes. Circ Res. 2002;91(6):532-539.

35. Steinberg SF. The cardiovascular actions of protease-activated receptors. Mol Pharmacol. 2005;67(1):2-11

36. Pawlinski R, et al. Protease-activated receptor-1 contributes to cardiac remodeling and hypertrophy. Circulation. 2007;116(20):2298-2306.

37. Strande JL, Hsu A, Su J, Fu X, Gross GJ, Baker JE. SCH 79797, a selective PAR1 antagonist, limits myocardial ischemia/reperfusion injury in rat hearts. Basic Res Cardiol. 2007;102(4):350-358.

38. Janeway CA Jr, Medzhitov R. Innate immune recognition. Annu Rev Immunol. 2002;20:197-216.
39. Seya T, Matsumoto M, Ebihara T, Oshiumi H. Functional evolution of the TICAM-1 pathway for extrinsic RNA sensing. Immunol Rev. 2009;227(1):44-53.

40. Bunting RA, et al. Novel antagonist antibody to TLR3 blocks poly(I:C)-induced inflammation in vivo and in vitro. Cell Immunol. 2011;poly(1):9-16.

41. Gorbea C, et al. A role for Toll-like receptor 3 variants in host susceptibility to enteroviral myocarditis and dilated cardiomyopathy. J Biol Chem. 2010;285(30):23208-23223.

42. Bonjardim CA, Ferreira PC, Kroon EG. Interferons: signaling, antiviral and viral evasion. Immunol Lett. 2009; 122(1):1-11.

43. Fensterl V, Sen GC. Interferons and viral infections. Biofactors. 2009;35(1):14-20.

44. Hengel H, Koszinowski UH, Conzelmann KK. Viruses know it all: new insights into IFN networks. Trends Immunol. 2005;26(7):396-401.

45. Johnsen IB, Nguyen TT, Bergstrom B, Lien E, Anthonsen MW. Toll-like receptor 3-elicited MAPK activation induces stabilization of interferon-beta mRNA. Cytokine. 2012;57(3):337-346.

46. Blauwet LA, Cooper LT. Myocarditis. Prog Cardiovasc Dis. 2010;52(4):274-288

47. Negishi H, et al. A critical link between Toll-like receptor 3 and type II interferon signaling pathways in antiviral innate immunity. Proc Natl Acad Sci U S A. 2008;105(51):20446-20451.

48. Riad A, et al. TRIF is a critical survival factor in viral cardiomyopathy. JImmunol. 2011;186(4):2561-2570.

49. Abston ED, et al. Th2 regulation of viral myocarditis in mice: different roles for TLR3 versus TRIF in progression to chronic disease. Clin Dev Immunol. 2012;2012:129486

50. Wessely R, Klingel K, Knowlton KU, Kandolf R. Cardioselective infection with coxsackievirus B3 requires intact type I interferon signaling: implications for mortality and early viral replication. Circulation. 2001;103(5):756-761.

51. Deonarain R, Cerullo D, Fuse K, Liu PP, Fish EN. Protective role for interferon-beta in coxsackievirus B3 infection. Circulation. 2004;110(23):3540-3543.

52. Kuhl U, et al. Interferon-beta treatment eliminates cardiotropic viruses and improves left ventricular function in patients with myocardial persistence of viral genomes and left ventricular dysfunction. Circulation. 2003;107(22):2793-2798.

53. Wang YX, et al. Antiviral and myocyte protective effects of murine interferon-beta and - $\{$ alpha 2 in coxsackievirus B3-induced myocarditis and epicarditis in Balb/c mice. Am J Physiol Heart Circ Physiol. 2007;293(1):H69-H76.

54. Le Goffic R, et al. Cutting Edge: Influenza A virus activates TLR3-dependent inflammatory and RIGI-dependent antiviral responses in human lung epithelial cells. J Immunol. 2007;178(6):3368-3372.

55. Stewart MJ, Smoak K, Blum MA, Sherry B. Basal and reovirus-induced beta interferon (IFN-beta) and IFN-beta-stimulated gene expression are cell type specific in the cardiac protective response. $J$ Virol. 2005;79(5):2979-2987.

56. Yuan J, et al. CXCL10 inhibits viral replication through recruitment of natural killer cells in coxsackievirus B3-induced myocarditis. Circ Res. 2009;104(5):628-638.

57. Weinzierl AO, et al. Effective chemokine secretion by dendritic cells and expansion of cross-presenting CD4-/CD8+ dendritic cells define a protective phenotype in the mouse model of coxsackievirus myocarditis. J Virol. 2008;82(16):8149-8160.

58. Moretti S, et al. The contribution of PARs to inflammation and immunity to fungi. Mucosal Immunol. 2008;1(2):156-168.

59. Shpacovitch V, Feld M, Hollenberg MD, Luger TA, Steinhoff M. Role of protease-activated receptors in inflammatory responses, innate and adaptive immunity. J Lenkoc Biol. 2008;83(6):1309-1322.
60. Shpacovitch V, Feld M, Bunnett NW, Steinhoff $M$. Protease-activated receptors: novel PARtners in innate immunity. Trends Immunol. 2007;28(12):541-550.

61. Rallabhandi P, et al. Analysis of proteinase-activated receptor 2 and TLR4 signal transduction: a novel paradigm for receptor cooperativity. J Biol Chem. 2008;283(36):24314-24325.

62. Nhu QM, Shirey KA, Pennini ME, Stiltz J, Vogel SN. Proteinase-activated receptor 2 activation promotes an anti-inflammatory and alternatively activated phenotype in LPS-stimulated murine macrophages. Innate Immun. 2012;18(2):193-203.

63. Nhu QM, et al. Novel signaling interactions between proteinase-activated receptor 2 and Tolllike receptors in vitro and in vivo. Mucosal Immunol. 2010;3(1):29-39.

64 . Khoufache K, et al. Protective role for proteaseactivated receptor-2 against influenza virus pathogenesis via an IFN-gamma-dependent pathway. Immunol. 2009;182(12):7795-7802.

65. Szalay G, et al. Ongoing coxsackievirus myocarditis is associated with increased formation and activity of myocardial immunoproteasomes. Am J Pathol. 2006;168(5):1542-1552

66. Zeng X, Moore TA, Newstead MW, Deng JC, Lukacs NW, Standiford TJ. IP-10 mediates selective mononuclear cell accumulation and activation in response to intrapulmonary transgenic expression and during adenovirus-induced pulmonary inflammation. J Interferon Cytokine Res. 2005;25(2):103-112.

67. Kirchhofer D, Moran P, Bullens S, Peale F, Bunting $\mathrm{S}$. A monoclonal antibody that inhibits mouse tissue factor function. J Thromb Haemost. 2005;3(5):1098-1099.

68. Pisegna S, Pirozzi G, Piccoli M, Frati L, Santoni A, Palmieri G. p38 MAPK activation controls the TLR3-mediated up-regulation of cytotoxicity and cytokine production in human NK cells. Blood. 2004;104(13):4157-4164.

69. Antoniak S, et al. Regulation of cardiomyocyte fulllength tissue factor expression and microparticle release under inflammatory conditions in vitro. $J$ Thromb Haemost. 2009;7(5):871-878.

70. Antao-Menezes A, Turpin EA, Bost PC, RymanRasmussen JP, Bonner JC. STAT-1 signaling in human lung fibroblasts is induced by vanadium pentoxide through an IFN-beta autocrine loop. $J$ Immunol. 2008;180(6):4200-4207.

71. Jaffre F, Friedman AE, Hu Z, Mackman N, Blaxall BC. Beta-adrenergic receptor stimulation transactivates protease-activated receptor 1 via matrix metalloproteinase 13 in cardiac cells. Circulation. 2012;125(24):2993-3003.

72. Schouten $\mathrm{M}$, et al. Activated protein $\mathrm{C}$ ameliorates coagulopathy but does not influence outcome in lethal H1N1 influenza: a controlled laboratory study. Crit Care. 2010;14(2):R65.

73. Lan RS, Stewart GA, Goldie RG, Henry PJ. Altered expression and in vivo lung function of proteaseactivated receptors during influenza A virus infection in mice. Am J Physiol Lung Cell Mol Physiol. 2004;286(2):L388-L398.

74. Richer MJ, Lavallee DJ, Shanina I, Horwitz MS. Toll-like receptor 3 signaling on macrophages is required for survival following coxsackievirus B4 infection. PLoS One. 2009;4(1):e4127.

75. Godeny EK, Gauntt CJ. Murine natural killer cells limit coxsackievirus B3 replication. J Immunol. 1987;139(3):913-918.

76. Hardarson HS, et al. Toll-like receptor 3 is an essential component of the innate stress response in virus-induced cardiac injury. Am J Physiol Heart Circ Physiol. 2007;292(1):H251-H258.

77. Chen D, et al. Protease-activated receptor 1 activation is necessary for monocyte chemoattractant protein 1-dependent leukocyte recruitment in vivo. 
J Exp Med. 2008;205(8):1739-1746.

78. Naldini A, Carney DH. Thrombin modulation of natural killer activity in human peripheral lymphocytes. Cell Immunol. 1996;172(1):35-42.

79. Palumbo JS, et al. Platelets and fibrin(ogen) increase metastatic potential by impeding natural killer cell-mediated elimination of tumor cells. Blood. 2005;105(1):178-185

80. Marchant D, McManus BM. Matrix metalloproteinases in the pathogenesis of viral heart disease. Trends Cardiovasc Med. 2009;19(1):21-26.

81. Cheung $\mathrm{C}$, et al. Ablation of matrix metalloproteinase-9 increases severity of viral myocarditis in mice. Circulation. 2008;117(12):1574-1582.

82. Connolly SJ, et al. Dabigatran versus warfarin in patients with atrial fibrillation. $N$ Engl J Med. 2009;361(12):1139-1151.

83. Morrow DA, et al. Vorapaxar in the secondary prevention of atherothrombotic events. $N$ Engl J Med. 2012;366(15):1404-1413.

84. Tricoci $\mathrm{P}$, et al. Thrombin-receptor antagonist vora- paxar in acute coronary syndromes. $N$ Engl J Med. 2012;366(1):20-33.

85. Darrow AL, et al. Biological consequences of thrombin receptor deficiency in mice. Thromb Haemost. 1996;76(6):860-866.

86. Kandolf R, Hofschneider PH. Molecular cloning of the genome of a cardiotropic Coxsackie B3 virus: full-length reverse-transcribed recombinant cDNA generates infectious virus in mammalian cells. Proc Natl Acad Sci U S A. 1985;82(14):4818-4822.

87. Smith AG, Sheridan PA, Harp JB, Beck MA. Dietinduced obese mice have increased mortality and altered immune responses when infected with influenza virus. J Nutr. 2007;137(5):1236-1243.

88. Antoniak S, et al. Protease-activated receptor 2 deficiency reduces cardiac ischemia/reperfusion injury. Arterioscler Thromb Vasc Biol. 2010;30(11):2136-2142.

89. Williams JC, Lee RD, Doerschuk CM, Mackman N. Effect of PAR-2 deficiency in mice on KC expression after intratracheal LPS administration. J Signal Transduct. 2011;2011:415195.
90. Owens AP 3rd, et al. Monocyte tissue factor-dependent activation of coagulation in hypercholesterolemic mice and monkeys is inhibited by simvastatin. J Clin Invest. 2012;122(2):558-568.

91. Boltzen U, et al. Alternatively spliced tissue factor and full-length tissue factor protect cardiomyocytes against TNF-alpha-induced apoptosis. J Mol Cell Cardiol. 2012;52(5):1056-1065.

92. Wang Y, et al. Inhibition of clathrin/dynamindependent internalization interferes with LPSmediated TRAM-TRIF-dependent signaling pathway. Cell Immunol. 2012;274(1-2):121-129.

93. Clark K, Plater L, Peggie M, Cohen P. Use of the pharmacological inhibitor BX795 to study the regulation and physiological roles of TBK1 and IkappaB kinase epsilon: a distinct upstream kinase mediates Ser-172 phosphorylation and activation. J Biol Chem. 2009;284(21):14136-14146.

94. Khoufache K, et al. PAR1 contributes to influenza A virus pathogenicity in mice. $J$ Clin Invest. 2013;123(1):206-214. 